\title{
Noradrenergic Dysregulation in the Pathophysiology of PTSD
}

\author{
Rebecca C. Hendrickson, MD, PhD ${ }^{1,2}$, Murray A. Raskind $\mathrm{MD}^{1,2}$ \\ ${ }^{1}$ VISN 20 Northwest Network Mental IIIness Research, Education and Clinical Center (MIRECC) \\ ${ }^{2}$ Department of Psychiatry and Behavioral Sciences, University of Washington School of Medicine
}

Key words: prazosin, posttraumatic stress disorder (PTSD), noradrenergic

Address correspondence to: Rebecca C. Hendrickson, MD, PhD, VA Puget Sound Health Care System, 1660 S. Columbian Way, S116 MIRECC, Seattle, WA 98108, rhend@uw.edu

(C) 2016. This manuscript version is made available under the Elsevier user license http://www.elsevier.com/open-access/userlicense/1.0/ 


\section{$\underline{\text { Abstract }}$}

A central role for noradrenergic dysregulation in the pathophysiology of post-traumatic stress disorder (PTSD) is increasingly suggested by both clinical and basic neuroscience research. Here, we integrate recent findings from clinical and animal research with the earlier literature. We first review the evidence for net upregulation of the noradrenergic system and its responsivity to stress in individuals with PTSD. Next, we trace the evidence that the $\alpha_{1}$ noradrenergic receptor antagnoist prazosin decreases many of the symptoms of PTSD from initial clinical observations, to case series, to randomized controlled trials. Finally, we review the basic science work that has begun to explain the mechanism for this efficacy, as well as to explore its possible limitations and areas for further advancement. We suggest a view of the noradrenergic system as a central, modifiable link in a network of interconnected stress-response systems, which also includes the amygdala and its modulation by medial prefrontal cortex. Particular attention is paid to the evidence for bidirectional signaling between noradrenaline and corticotropinreleasing factor (CRF) in coordinating these interconnected systems. The multiple different ways in which the sensitivity and reactivity of the noradrenergic system may be altered in PTSD are highlighted, as is the evidence for possible heterogeneity in the pathophysiology of PTSD between different individuals who appear clinically similar. We conclude by noting the importance moving forward of improved measures of noradrenergic functioning in clinical populations, which will allow better recognition of clinical heterogenetiy and further assessment of the functional implications of different aspects of noradrenergic dysregulation.

\section{$\underline{\text { Introduction }}$}

Our understanding of the role of noradrenergic signaling in the pathophysiology of PTSD has emerged from a process of repeatedly integrating research results and clinical observations. Drawing on both direct and indirect evidence that increased central nervous system (CNS) noradrenergic tone may underlie many of the symptoms of post-traumatic stress disorder (PTSD), we hypothesized that blockade of noradrenergic transmission might be able to treat the nightmares that posed one of the most impairing and treatment-resistant symptoms observed in his patient population. Clinical case series followed by formal clinical trials confirmed that in particular prazosin, a clinically available antagonist of the postsynaptic $\alpha_{1}$ noradrenergic receptor, was effective for both night and daytime symptoms of PTSD. Here, we will review this initial evidence as well as the ongoing exploration of the mechanism for these effects in animal models, in order to develop an overall conceptualization of the role of increased noradrenergic tone in the pathophysiology of PTSD.

\section{Noradrenaline and the biologic response to stress}

Noradrenaline, along with its methylation product, adrenaline, is perhaps the paradigmatic example of a neuromodualtory neurotransmitter system. Peripherally, noradrenaline (abbreviated here as NA, and also known as norepinephrine or NE) was first known for its ability to effect a rapid and coordinated response from multiple end organs in response to acute stress, forming a central component of the idea of a sympathoadrenal system that coordinated the 'fight or flight' response (Johnson et al. 1992). The exploration of this system facilitated the development of a concept of 'stress' that crossed physical and 
cognitive categories (Anderson, Sinkey, and Mark 1991; Selye 1973; Tsigos and Chrousos 2002). As increasing appreciation developed of the role of noradrenaline in more specific neuronal circuits, including central nervous system (CNS) circuits, more localized activation and regulation of noradrenergic signaling was also recognized (Beissner et al. 2013; Morilak et al. 2005; Sara and Bouret 2012). In humans, the dominant CNS source of noradrenaline was identified as the locus coeruleus (LC), in the rostral pons (Bogerts 1981; Dahnlstrom and Fuxe 1964; Szabadi 2013).

Noradrenaline is only one of a larger group of structurally-related neurotransmitters, the monoamines; other major monoaminergic neurotransmitters include dopamine (from which noradrenaline is synthesized), histamine, serotonin and melatonin. In general, monoaminergic neurotransmitters are involved centrally in the regulation of both alertness and emotion/mood, and there is evidence that many of them may have some role in the pathophysiology or treatment of persistent sequelae following trauma (Agorastos and Linthorst 2016; Bernardy and Friedman 2015; Fernandez and Gaspar 2012; Hoskins et al. 2015; Xing, Li, and Gao 2016). Consistent with its particularly direct connection to the biologic response to direct threat, however, the evidence connecting noradrenaline to the pathophysiology is arguably the strongest and most direct, and will be the focus of this review.

\section{Evidence of increased noradrenergic tone in PTSD}

\section{Evidence of increased sympathetic or noradrenergic tone in the peripheral nervous system}

Initial indications of increased noradrenergic signaling in PTSD came from evidence of increased peripheral sympathetic nervous system activity (Krystal and Neumeister 2009; Michopoulos, Norrholm, and Jovanovic 2015; Strawn and Geracioti 2008; Zoladz and Diamond 2013). In 1982, Blanchard and colleagues observed significantly higher heart rate (HR) and systolic blood pressure (SBP) in 11 Veterans with PTSD as compared with 11 age and sex matched controls (Blanchard et al. 1982). The temporal plots of their data suggest that for HR and SBP in particular, the Veterans both started with higher baseline HR and SBP, and sustained the increases they experienced in response to stressors for a substantially longer period of time than the control subjects. The following year, Malloy and colleagues reported a similar pattern of both higher baseline HR and mean skin resistance responses at baseline, and much higher responsivity to stressful cues (Malloy, Fairbank, and Keane 1983). Although increased resting HR and BP has been heterogeneous at the level of individual studies (see eg (McFall, Veith, and Murburg 1992) versus (Israel Liberzon et al. 1999)), meta-analytic review has supported the presence of increases in resting BP for both systolic (Pole 2007) and diastolic (Buckley and Kaloupek 2001; Pole 2007) values. More recent epidemiologic data have also provided support for these connections, with increased rates of hypertension diagnoses reported in those found to have PTSD in the large US national comorbidity survey, even when controlling for age, smoking and comorbid depression (Kibler, Joshi, and Ma 2009)

As would be expected given the reciprocal inhibition between the sympathetic and parasympathetic nervous systems, cardiovascular parameters frequently used as indicators of parasympathetic tone have also been found to be decreased in strength in individuals with PTSD, including decreased high frequency heart rate variability at rest (Minassian et al. 2014) and in response to a psychological stressor 
(Keary, Hughes, and Palmieri 2009), decreased baroreceptor reflex sensitivity (Hughes, Feldman, and Beckham 2006) and decreased respiratory sinus arrhythmia (Woodward et al. 2009). Salivary alpha amylase (sAA) levels are also often considered an indication of the balance of sympathetic nervous system activation and parasympathetic withdrawal (Nater and Rohleder 2009), although their exact relationship with these systems (Bosch et al. 2011), versus central (Ehlert et al. 2006) or peripheral (Myriam V. Thoma et al. 2012; Turner and Sugiya 2002) noradrenergic tone in particular, versus other aspects of the stress-response pathway (Myriam V. Thoma et al. 2012) remains unclear. Nonetheless, SAA levels have been repeatedly found to be altered at baseline and following a stressor in populations diagnosed with PTSD (Feldman et al. 2013; Nicholson, Bryant, and Felmingham 2014), particularly when circadian patterns of release are assessed (Keeshin et al. 2015; Myriam Verena Thoma et al. 2012), and correlations between individuals' patterns of SAA have also in some studies been found to correlate with general PTSD symptom intensity and in particular hyperarousal and intrusive symptoms (Chou et al. 2014; Keeshin et al. 2015).

Direct measurements of peripheral noradrenaline in urine have also found differences between those with PTSD and various comparison groups including healthy controls, trauma-exposed controls without PTSD, and individuals with other psychiatric diagnoses. In 1987, Kosten, Mason and colleagues assessed 24 hours urinary NA and adrenaline concentrations in a population of 44 psychiatric inpatients, and found that the urinary NA levels upon initial admission to the hospital were dramatically elevated in both those with PTSD and with mania $(73 \pm 12 \mu \mathrm{g} /$ day and $81 \pm \mu \mathrm{g} /$ day, respectively) as compared to those with major depressive disorder (MDD; $49 \pm 5 \mu \mathrm{g} /$ day), paranoid schizophrenia ( $41 \pm 9 \mu \mathrm{g} /$ day) or undifferentiated schizophrenia $(43 \pm 10 \mu \mathrm{g} / \mathrm{day})$ (Kosten et al. 1987). Providing further support for there being some specificity of this finding for by diagnosis, in 1992 Yehuda and colleagues found higher 24hour urine catecholamine levels in those with PTSD compared to those without, and that dopamine and NA both correlated with the severity of PTSD symptoms within the PTSD group, particularly the intrusive symptoms, but not with symptoms of depression. More recent results have extended these findings to civilian PTSD and to women (Young and Breslau 2004), demonstrated that the increased urine noradrenaline is true across 3 independent 8 hour urinary samples (Young and Breslau 2004), and found that the increased urinary noradrenaline is specific for those with current as opposed to lifetime PTSD or a history of trauma exposure without PTSD (Wingenfeld et al. 2015; Young and Breslau 2004).

Studies assessing plasma NA are more limited, but have found higher levels both at baseline (Israel Liberzon et al. 1999) and in response to trauma-related cues in those with PTSD as compared to traumaexposed individuals without PTSD (Blanchard et al. 1991; Israel Liberzon et al. 1999) (see also study by Southwick and colleagues, described below). Of note, however, one group of researchers that noted that studies that allowed for a longer resting period prior to assessing baseline indicators of autonomic function were more likely to have a negative result, and thus carried out an assessment of plasma NA dynamics with a prolonged wait time prior to the initiation of measurement, found lower baseline (at quiet rest) levels of plasma NA in subjects with combat PTSD than in controls (Murburg et al. 1995) - a finding reinforcing the importance of considering models of altered dynamics of release and response to noradrenaline, not simply baseline changes. 


\section{Evidence for increased noradrenergic tone in the CNS}

The most direct assessment of central noradrenergic tone in individuals with PTSD as compared with control subjects was done by Geracioti and colleagues, who took hourly CSF samples over a 6 hour period from male combat Veterans with PTSD and healthy controls, and found significantly higher CSF noradrenaline concentrations in the subjects with PTSD (Geracioti et al. 2001). They also found that in the patients with PTSD, mean CSF noradrenaline levels correlated positively and strongly with the total symptom ratings on the Clinician-Administered PTSD Scale scores (CAPS; $r=.82, p<.005$ ). A more recent study by the same research group followed CSF noradrenaline concentrations in eight subjects with warrelated PTSD found that watching a combat-themed video led to increased CSF NA concentrations that persisted for several hours, during which time the degree of elevation in CSF noradrenaline was correlated with subjective worsening of $\operatorname{mood}(r=-.857, p=.006)$ (Geracioti et al. 2008). In addition, both baseline and maximum CSF noradrenaline concentrations correlated with baseline and maximum heart rate, respectively, in both the combat-themed and a neutral video session - results consistent with the previously supposed relationship between increased central noradrenergic tone and peripheral sympathetic activation in this population. Increased pupil diameter has also been found to correlate with central noradrenergic function in general and locus coeruleus noradrenergic function in particular (Joshi et al. 2016; Murphy et al. 2011, 2014), and in two small studies has been found to be increased in those with PTSD or PTSD symptoms compared with controls, particularly in response to threatening stimuli (Cascardi et al. 2015; Kimble et al. 2010).

Connections between PTSD symptoms and measures of both central and peripheral noradrenergic activation can also be queried using pharmacologic provocation. An innovative study published by Southwick and colleagues in 1993 measured the NA metabolite MPHG in plasma as an estimate of overall (central and peripheral) presynpatic NA outflow in response to a pharmacologic challenge with the $\alpha_{2}$ AR antagonist yohimbine - which is expected to exert much of its effect by blocking presynaptic $\alpha_{2}$ adrenergic autoreceptors, thus increasing the release of noradrenaline (Southwick et al. 1993). They also assessed subjective and physiologic responses to this pharmacologic challenge. Although they found only a small, not statistically significant difference between baseline MHPG levels in those with PTSD and those without PTSD, both the magnitude and duration of the increase in response to yohimbine was significantly larger in those with PTSD as compared to control subjects. In addition, $70 \%$ of those with PTSD - but no control subjects - experienced panic attacks, and 40\% of those with PTSD but no control subjects - experienced flashbacks. Subjective ratings of PTSD symptoms altogether, emotional numbing, intrusive thoughts and grief all increased substantially in those with PTSD but not controls, as did heart rate and both sitting and standing blood pressure. For each of these physiologic parameters, the effect was larger in those who experienced a yohimbine-induced panic attack than those who did not. A subsequent study by many of the same researchers and with a related study design replicated the finding of significantly increased anxiety in subjects with PTSD as compared to control subjects in response to a moderate dose of yohimbine, and, using PET monitoring of whole-brain glucose metabolism, found patterns of decreased cortical metabolism in subjects with PTSD in areas where control subjects generally responded with increased metabolism unless given a significantly 
higher dose of yohimbine, providing further evidence consistent with increased noradrenergic signaling in response to yohimbine in subjects with PTSD (J. D. Bremner et al. 1997).

These results are highly consistent with increased noradrenergic signaling in those with PTSD, and a meaningful relationship between that increased signaling and the subjective symptoms of PTSD. In addition, they have a number of more subtle but interesting implications. First, the increased plasma MHPG in response to equivalent doses of $\alpha_{2}$ AR agonism suggests that beyond a simple tonic increase in baseline locus coeruleus firing rates, there may be a functional upregulation of noradrenergic signaling capacity, either via increased gain control somewhere in the regulatory pathway connecting central noradrenergic signaling with peripheral sympathetic activation, or via a cellular mechanism such as increased neurotransmitter synthesis or release. Second, the disproportionately larger increase in subjective symptoms compared to the increase in MHPG concentrations is suggestive of an increased sensitivity to this increased noradrenergic outflow, as well. Finally, the larger effect of $\alpha_{2}$ agonism on those with PTSD than without is less consistent with a model where the increased noradrenergic tone in PTSD is secondary to a downregulation of $\alpha_{2}$ ARs. Together, these last two points particularly implicate the possibility of upregulation or increased sensitivity of postsynaptic ARs, particularly $\alpha_{1}$ or $\beta$ ARs, as a mechanism for persistent and symptom-associated alteration of the noradrenergic system in those with PTSD.

A final line of evidence suggesting a role for altered noradrenergic signaling in the development of PTSD symptoms comes from assessment of the primary reuptake channel for noradrenaline, the Norepinephrine Transporter (NET). Based on findings in rodent models, where repeated stress was found to decreased NET availability in both LC and limbic brain regions (Tejani-Butt, Pare, and Yang 1994; Zafar et al. 1997), it was postulated that decreased NET concentration, leading to increased noradrenaline concentrations in synapses, could be one mechanism for increased noradrenergic tone in PTSD. Although the density of NET in most brain regions is too diffuse for reliable detection by the PET ligands that have been developed so far, one recent study was able to assess differences in NET density within the locus coeruleus in individuals with PTSD, in individuals who were exposed to traumatic events but did not develop PTSD, and in control subjects without a history of exposure to trauma (Pietrzak et al. 2013). Consistent with animal studies, they found a significant reduction in the density of NET labeled in the LC in those with PTSD as compared with non-trauma exposed controls, with the trauma-exposed control group having an intermediate picture. Furthermore, a brief subsequent report by the same researchers documented in an independent data set the complementary finding that the number of copies of a single-nucleotide polymorphism in the promotor region of the NET gene that had been previously linked to panic disorder was strongly associated with the presence of anxious arousal symptoms, but not to any other type of PTSD symptoms (Pietrzak et al. 2015). These findings were felt to be in support of the idea that decreased NET density following traumatic exposure was part of the mechanism leading to high noradrenergic tone and the generation of PTSD symptoms. Surprisingly, however, the density of NET staining in the PTSD group was positively correlated with specifically the anxious arousal subgroup of PTSD symptoms, a finding the authors interpreted as indicating attempted compensation. This finding reinforces that even within the model of increased noradrenergic signaling 
as a fundamental mechanism contributing to the development of PTSD symptoms, the disruption should be viewed as most likely to be a process of dysregulation, rather than simple upregulation.

\section{Evidence for increased noradrenergic tone during sleep in PTSD}

Given the prominence of nighttime and sleep symptoms in PTSD, in combination with the evidence for generally increased noradrenergic tone in PTSD and the known prominent decrease in noradrenergic signaling during sleep in healthy individuals ((Brown et al. 2012), see also below), inappropriately preserved noradrenergic signaling during deep and REM sleep has been a prominent part of many theories of PTSD pathophysiology (Spoormaker and Montgomery 2008; Vanderheyden, Poe, and Liberzon 2014; Walker and van der Helm 2009). In light of the hints above, however, that noradrenergic signaling may be dysregulated more than generally upregulated, it is worth looking independently at the current state of evidence supporting the presence of increased noradrenergic signaling during sleep in those with PTSD.

Two studies that have directly assessed nighttime noradrenaline concentrations in those exposed to trauma and in relationship to symptoms of sleep disruption. In 1987, in an otherwise largely negative study, Davidson and colleagues noted that sleep-derived noradrenaline concentrations were increased relative to daytime values in those reporting sleep disruption following exposure to a trauma, while sleep-derived values were decreased relative to daytime values in control subjects (Davidson, Fleming, and Baum 1987). Following up on this suggestive result, Mellman and colleagues measured urinary noradrenaline and MHPG (felt to provide more indication of central NA levels than urinary NA itself) in eight hour segments in 20 subjects with combat PTSD and eight control subjects, while also carrying out overnight polysomnography (Mellman et al. 1995). They found no significant difference in 24 hour or nocturnal NA or MHPG levels when directly compared between the two groups, but, consistent with Davidson and colleagues' earlier findings, found that mean nocturnal MHPG levels were higher than mean daytime levels for those with PTSD, yet lower than daytime levels for control subjects, a difference that was statistically significant $(p<.03)$. Furthermore, the nocturnal minus daytime MHPG difference was significantly negatively correlated with total sleep time (for those with PTSD) and sleep efficiency (in controls), consistent with a failure to decrease noradrenergic signaling at night playing a role in sleep disruption in both groups. Alternatively, a similar result could be produced if sleep disruption from an alternative cause resulted in increased time awake during the 8 hour period of nocturnal collection, and this increased time awake resulted in both increased central noradrenergic signaling during the nighttime and, potentially, decreased alertness and noradrenergic signaling during the daytime periods.

Measures of autonomic activity, a particularly accessible measure during sleep, have also been used to provide some measure of noradrenergic signaling during sleep. Increased heart rate during sleep has been found in those with PTSD as compared with healthy controls (Bertram et al. 2014; van Liempt et al. 2013; Woodward et al. 2009), including trauma-exposed controls without PTSD (van Liempt et al. 2013). A failure to decrease blood pressure by at least $10 \%$ from daytime levels has also been found to be associated with a lifetime diagnosis of PTSD or subclinical PTSD symptoms in one study of urban African American men (Mellman et al. 2009), and to be associated not with current PTSD diagnosis but with hyperarousal symptoms and poor sleep quality in particular in a sample of women with predominantly 
civilian PTSD (Ulmer et al. 2013). Finally, in one of the studies that found increased nighttime heartrate in those with PTSD a decrease in respiratory sinus arrhythmia - an indication of parasympathetic tone was found to be lower in that group compared with controls (Woodward et al. 2009), while in a sample of individuals assessed within one month of a traumatic experience, those with high PTSD-like symptoms were found to have an increase in the ratio of low frequency to high frequency heart rate variability during REM sleep, consistent with increased sympathetic tone (Mellman et al. 2004). A recent study which found decreased normalized high frequency heart rate variability - considered a measure of parasympathetic tone and lower activation of the locus ceruleus (Napadow et al. 2008) - in those with PTSD as compared with trauma-exposed subjects without PTSD was notable, however, for not finding any significant difference in overnight heart rate or the ratio of low frequency to high frequency heart rate variability (Kobayashi, Lavela, and Mellman 2014), further underscoring the likely heterogeneity of individuals on these measures.

Early evidence for the efficacy of pharmacologic manipulation of the noradrenergic system in treating PTSD

Based on the earlier of the above findings, clinicians in the 1980s began using trying out a number of pharmacologic modulators of noradrenergic signaling in patients with PTSD. In the mid-1980s, two groups reported improvement in general PTSD symptoms in small open-label case series of propranolol in both combat Veterans (Kolb, Burns, and Griffiths 1984) and children with a history of abuse (Famularo, Kinscherff, and Fenton 1988). In parallel with this, Kinzie and colleagues began using the $\alpha_{2}$ AR agonist clonidine in Cambodian refugees with a history of trauma exposure, and published a large case series of 68 patients describing significant improvements PTSD symptoms in general and sleep in particular (Belkin and Schwartz 2015; Kinzie and Leung 1989). The same research group published a pilot study of 4 patients who underwent overnight polysomnography both before and after the initiation of clonidine, which found improved sleep and an almost total cessation of nightmares (Kinzie, Sack, and Riley 1994). Another $\alpha_{2} A R$ agonist that is more specific for the $\alpha_{2 A} A R$, guanfacine, also showed promise in treating PTSD symptoms in case reports (Horrigan and Barnhill 1996) and, more recently, in an openlabel trial of an extended release preparation (Connor et al. 2013), although two randomized controlled trials of the standard formulation failed to demonstrate significant benefit (Davis et al. 2008; Neylan et al. 2006). While no randomized controlled trials of clonidine for PTSD have been reported, and its use has been limited by side effects - particularly sedation (van Zwieten 1999) - these early findings, in combination with the more basic research findings above, provided further support for the hypothesis that increased noradrenergic signaling played a meaningful role in the pathophysiology of PTSD.

\section{Clinical and preclinical evidence for the efficacy of prazosin for symptoms of PTSD and commonly comorbid disorders}

\section{Motivation for and initial clinical experience with prazosin in PTSD}

The initial use of prazosin for PTSD was motivated by a need for new treatments to address nighttime symptoms of PTSD. Sleep disturbances in general and recurrent trauma nightmares with distressed awakenings in particular have long been recognized as a hallmark of PTSD (Ross et al. 1989). These 
symptoms are often particularly resistant to treatment, with persistent sleep complaints present in approximately half of even those considered "complete responders" to evidence-based psychotherapy for PTSD (Zayfert and DeViva 2004), and limited evidence supporting most commonly used pharmacotherapies (Nappi, Drummond, and Hall 2012). Consistent with this, when the author MR was in 1996 providing ongoing clinical care to an African American Vietnam Was combat Veterans group therapy program (Jones et al. 2000), he observed that sleep disruption and trauma nightmares were these Veterans' most troublesome and treatment refractory PTSD symptoms.

The Veterans' subjective reports of their nighttime sleep disruption were often very similar among individuals. The most salient feature was distressed awakenings, which were usually, but not always, coincident with trauma-content nightmares. Furthermore, consistent with previous reports (Inman, Silver, and Doghramji 1990; Kramer and Kinney 1988), these Veterans reported striking physiologic responsivity accompanying the nightmares and distressed awakenings, including intense sweating, rapid heart rate, shortness of breath, fearfulness, and hypervigilance. This constellation of experiences was so characteristic that the Veterans often referred to this state as being an "adrenaline storm". Based on these descriptions and given the data above suggesting a role for increased noradrenergic signaling in PTSD, pharmacological modulation of noradrenergic signaling was considered as a possibility for providing symptomatic relief. Conceptually one could achieve this either by agonizing presynpatic autoreceptors to decrease noradrenergic release into the synapse, or antagonizing postsynaptic receptors to block the response to noradrenaline. The later course was thought to be the better initial choice based on the previously discussed results by Southwick and colleagues suggesting a larger role for increased AR sensitivity than increased NA release (Southwick et al. 1993). As there were at this time several published reports of the $\beta A R$ antagonist propranolol having some efficacy for PTSD in the open-label trials discussed above (Famularo et al. 1988; Kolb et al. 1984), but no previously published reports of beneficial behavioral effects following $\alpha_{1}$ AR antagonism, it was tried first.

The first Vietnam Veteran treated for intractable PTSD symptoms with a postsynaptic AR antagonist, in 1996, had suffered nightly severe trauma nightmares and sleep disruption, accompanied by sweating, hypervigilance and inability to return to sleep, for decades. Like many Veterans, his nightmares graphically "replayed" his combat traumas; for him, these worsened his intense remorse over the tragic combat-related death of a close friend, and he developed episodic suicidal ideation and alcohol dependence. As his nightmares and sleep disruption had already been unresponsive to multiple psychotropic medications and psychotherapies, author MR prescribed the postsynaptic $\beta$ AR antagonist propranolol 20mg twice daily. After two weeks of use, however, the Veteran reported that his nightmares had actually intensified. Further review of the literature revealed that nightmares are a reported occasional adverse effect of propranolol and other $\beta$ AR antagonists (McAinsh and Cruickshank 1990; Westerlund 1985), but also that in several neurobiologic systems, the $\alpha_{1}$ AR and $\beta$ ARs can have opposing effects (Basile and Dunwiddie 1984; Day, Randle, and Renaud 1985) - raising the possibility that the CNS brain active $\alpha_{1} A R$ antagonist prazosin might instead have the desired effect. And, indeed, after the propranolol was discontinued and prazosin was, over three weeks, titrated from $1 \mathrm{mg}$ to $8 \mathrm{mg}$ at bedtime, the Veteran reported complete cessation of his trauma nightmares, an increase of total sleep duration from 3 hours to 6 hours, and in fact the resumption of "normal" dreaming that had been 
absent since his Vietnam deployment. Furthermore, as his sleep improved, his suicidal ideation stopped, and he became abstinent from alcohol.

At this point, the Veteran observed that he was experiencing a reemergence of his irritability and hypervigilance every afternoon. Addition of prazosin $5 \mathrm{mg}$ midmorning and mid-afternoon greatly reduced these daytime hyperarousal symptoms, but was accompanied by a modest tachycardia (100 to 110 beats/min). To address this presumed reflex tachycardia response to prazosin, propranolol was reintroduced at $20 \mathrm{mg}$ BID. Fortunately, in the context of preexisting $\alpha$ AR blockade not only did this not lead to a reemergence of nightmares, but was felt by the Veteran to result in further subjective improvement in irritability and hypervigilance. Author MR has continued to follow this Veteran from 1996 to the present, during which time he has remained abstinent from alcohol and without reemergence of his previous symptoms, on a continuous and stable regimen of prazosin and propranolol.

The second Vietnam Veteran treated with prazosin presented with severe and treatment resistant trauma nightmares, sleep disruption, alcohol dependence and suicidal ideation of similar intensity and frequency to those of the first Veteran described above. These symptoms as well resolved completely on a regimen of prazosin $5 \mathrm{mg}$ twice daily and $10 \mathrm{mg}$ at bedtime. Again a mild tachycardia was noted and treated with propranolol without the recurrence of trauma nightmares. This Veteran as well became abstinent from alcohol, and has remained so for the past 19 years on a continuous, stable regimen of prazosin and propranolol. These responses were further noted to be consistent with the experience of two other Veterans' spontaneous reports of markedly reduced PTSD trauma nightmare intensity and improved sleep following initiation of prazosin for BPH urinary outflow symptoms. Together, they prompted a series of open label case series (Peskind et al. 2003; Raskind et al. 2000; Taylor and Raskind 2002), which - along with a chart review study (Raskind et al. 2002) - provided further justification for pursuing formal randomized controlled trials (RCTs) of prazosin for PTSD.

\section{Clinical trials of Prazosin for PTSD}

There are six RCTs of prazosin for PTSD that have been published - four by the authors' research group, and two by independent research teams (see Table 1). All six studies have had a positive result for prazosin as compared to placebo on at least one reported primary outcome, as well as often on multiple secondary outcomes.

The first two RCTs were done in Vietnam combat Veterans, a population where the PTSD symptoms being targeted had generally been chronic and treatment resistant for decades. In these studies, prazosin was administered as a single nighttime dose, specifically to target primary outcome measures of persistent and distressing trauma-related nightmares and sleep disruption. As prazosin has an duration of action of $~ 6-10 \mathrm{~h}$ (Grahnen et al. 1981), nighttime doses alone were not expected to have a significant direct effect on daytime symptoms; however, an additional primary outcome measure of Clinical Global Impression of Change (CGIC) (Guy 1976) was included to determine if the impact of 
nightmare reduction and sleep improvement was reflected in an overall improvement in global clinical status as reflected in function at home and work.

The first of these trials was a double-blind placebo-controlled crossover study in ten Veterans with chronic PTSD (Raskind et al. 2003), all with frequent and distressing trauma nightmares as represented by a score of at least 6 out of 8 on the Clinician-Administered PTSD Scale (CAPS) (Blake et al. 1995) item quantifying recurrent distressing dreams. Their baseline levels of overall PTSD symptoms were severe, with mean baseline total CAPS score of more than 80 . Prazosin or placebo in were begun at $1 \mathrm{mg}$ nightly and titrated upward over three weeks to a dose that eliminated trauma nightmares or a maximum dose of $10 \mathrm{mg}$ nightly (mean achieved prazosin dose $9.6 \mathrm{mg}$ ). This was continued for 6 additional weeks, then subjects underwent a two week washout period before crossing over to the other arm. Sleep primary outcome measures were scores on the CAPS items addressing recurrent distressing dreams and difficulty falling/staying asleep, and on both prazosin was significantly better than placebo $(p<.01$, effect size $(E S)>1.5)$. CGIC was also significantly more improved on prazosin than on placebo $(p<.01, E S=1.4)$. Significantly more improvement was also seen on secondary endpoints addressing individual symptom clusters and total CAPS score. The largest difficulty during the trial was that all five of the subjects who began with the active drug and were then crossed over to placebo complained of rapid return of distressing nightmares during prazosin washout, and four of these five insisted on discontinuing the study so they could be given open-label prazosin.

The second RCT addressing nighttime PTSD symptoms in Veterans was a parallel group placebo controlled study in 40 Veterans with chronic PTSD and significant sleep disturbance ( $\geq 5$ on CAPS sleep and disturbing dreams items; mean baseline CAPS $70 \pm 20$ ) (Raskind et al. 2007). Prazosin or placebo were titrated over 4 weeks to either full efficacy or a maximum dose of $15 \mathrm{mg}$ at bedtime (mean achieved prazosin dose $13 \pm 3 \mathrm{mg}$ ) and maintained for 8 weeks. Again prazosin was significantly more effective than placebo on all three primary endpoints - the CAPS distressing dreams item, the Pittsburgh Sleep Quality Index (PSQI) (Buysse et al. 1989), and the CGIC score - all with large effect sizes (Cohen's d all >0.9). On secondary endpoints, subjects on prazosin reported a change in dream type as assessed by the PTSD Dream Rating Scale (Esposito et al. 1999) from characteristics typical of trauma nightmares to those typical of normal dreaming. There was a trend towards a reduction in the total number of distressing dreams, but the reduction was only statistically significant for trauma-related nightmares in particular. There was also a trend towards reduction in both total CAPS scores and depression symptoms, although these also did not reach statistical significance. In both this and the previous study, prazosin was well tolerated.

The next two RCTs of prazosin for PTSD symptoms added in direct quantitative measurements of sleep duration and architecture. The first of these, carried out by the authors' research group in collaboration with a Dr. Fletch Taylor, a Puget Sound area private practice psychiatrist who had independently noticed beneficial effects of prazosin on PTSD trauma nightmares, was also the first to test prazosin in civilian trauma PTSD (Taylor et al. 2008). In this study, 13 subjects with civilian trauma PTSD with severe trauma nightmares and sleep disturbance ( $\geq 4$ on CAPS sleep/nightmare items) were randomized to prazosin or placebo in a double-blind crossover trial. Trauma type included childhood sexual or physical abuse $(n=8)$ 
as well as adult traumas $(n=5)$. Subjects were required to score at least a 40 on the PTSD ChecklistCivilian Version (PCL-C; mean PCL of randomized participants at baseline $=59 \pm 13$ ) (Forbes, Creamer, and Biddle 2001). Prazosin or placebo was titrated over only 10 days, with a mean achieved dose of $3.1 \mathrm{mg} \pm 1.3 \mathrm{mg}$ (range $2-6 \mathrm{mg}$ ), and the achieved dose was maintained for 11 days before the subject was crossed over to the opposite arm. Objective sleep measurement was carried out for the last 3 days of each treatment arm using the two-lead portable REMView device, which is able to distinguish REM sleep, non-REM sleep and wake, with high agreement with traditional polysomnography measures (Ajilore et al. 1995; Edinger et al. 2004).

The results of this study found both subjective and objective improvements in sleep when subjects were on prazosin as compared with placebo. Although change sleep onset latency did not differ significantly between the two conditions, total sleep time was increased by more than 90 minutes more (30\%) on prazosin than on placebo, and total REM time by more than $40 \%$ more (both $p<.01$ ). Consistent with previous results, subjective measures of sleep quality were also higher on prazosin than on placebo, with significant improvement on the CAPS "recurrent distressing dreams" item, non-nightmare distressed awakenings, CGI scores, and PTSD dream rating scale, all with P $\leq .05$ and Cohen's $d$ values ranging from 0.96 to 1.5; PCL-C also improved significantly more while on prazosin than on placebo with a $p<.03$ and a Cohen's $d$ of 0.79. Adverse events did not differ between conditions. The improvement in objective as well as subjective sleep measures was consistent with the idea that prazosin was effective via blocking the disruption of REM sleep by inappropriately elevated CNS noradrenergic activity, and by doing so was able to prevent not just subjective distress about memories but the actual sleep fragmentation and disruption, as well.

The other published trial to include quantitative assessment of sleep during treatment with prazosin was done by an independent research group. In this trial, Germain and colleagues randomized 50 Veterans with chronic sleep disturbances to one of three conditions: prazosin, placebo, or an eight week behavioral sleep intervention (BSI) that included using actigraphy to track adherence to recommendations throughout the two month period (Germain et al. 2012). Inclusion criteria included a score of at least 3 on the nightmare item of the CAPS and total score of greater than 5 on the PSQI. Participants randomized to prazosin were titrated to a maximum of $15 \mathrm{mg}$ nightly over 6 weeks (mean obtained $=8.9 \mathrm{mg}$ ), which was then maintained for an additional two weeks. Primary outcome measures included subjective ratings of sleep and function plus a sleep diary; subjects were also assessed at baseline and completion via overnight PSG.

The results of this study provide an interesting complement to those of Taylor et al. Overall, both active treatment groups showed significantly greater improvements in insomnia rating scales, and trends towards greater improvements in daytime PTSD symptom ratings and global clinical improvement scales, but without significant differences identified between the two treatments. The objectively measured sleep parameters showed no significant differences, although there were non-significant trends towards larger improvements in total sleep time and sleep latency in the prazosin group as compared to the placebo group, and in fact in the placebo group as compared to the BSI group. Interestingly, there also appeared to be a trend towards larger discrepancies between subjective and 
objective reports in the BSI group as compared to the prazosin and placebo groups, with final selfreported sleep-efficiency and total sleep time being highest in the BSI group and lowest in the placebo group, while final objectively measured sleep-efficiency and total sleep time were the lowest in the BSI group and highest in the prazosin group.

One potential explanation for some of the differences in the results between the Taylor et al and Germain et al studies may lie in the populations being examined. Consistent with the absence of a requirement for a diagnosis of PTSD and a lower CAPS nightmare item requirement in Germain and colleauges' inclusion criteria, with mean baseline PCL scores of 36.6, 43.9 and 35.0 for the BSI, prazosin and placebo groups respectively, the majority of the participants in their study would not have qualified for Taylor and colleagues' study, and were well below their mean baseline PCL score of 59. Similarly, with baseline total sleep time by PSG of $\sim 350$ minutes, these individuals' total sleep times were well above the mean total sleep time on placebo of $\mathbf{2 8 0}$ minutes in Taylor et al's study, and nearly at the mean final total sleep time on prazosin of 374 minutes. Thus, the combination of these two studies raises the possibility that the efficacy of prazosin for disrupted sleep following trauma may be either decreased or less consistent in a less severely affected population. At the same time, the fact that there were nonetheless statistically significant improvements on their primary outcome measures for both active interventions, despite the significantly different presumed mechanisms of action, prompts the so far unanswered question of whether the combination may be more effective than either treatment alone.

Although the initial clinical experience with prazosin had involved the addition of daytime doses to boost the efficacy of prazosin for daytime PTSD symptoms, a daytime does was not included in any of the RCTs of prazosin for PTSD symptoms until the fifth trial, done in active-duty soldiers returned from combat deployments in Iraq and Afghanistan (Raskind et al. 2013). 67 soldiers (57 men, 10 women) who met criteria for PTSD, with frequent and severe combat trauma nightmares that had started subsequent to their traumatic combat event(s) in Iraq and Afghanistan, were randomized to prazosin or placebo for 15 weeks. Prazosin was titrated over six weeks until trauma nightmares were absent or to a maximum dose of $5 \mathrm{mg}$ midmorning and $20 \mathrm{mg}$ at bedtime for men, or $2 \mathrm{mg}$ and $10 \mathrm{mg}$ for women (mean achieved doses $4.0 \mathrm{mg} / 15.6 \mathrm{mg}$ and $2 \mathrm{mg} / 7.9 \mathrm{mg}$ ). Prazosin was significantly more effective at reducing scores on the CAPS recurrent distressing dreams item, PSQI, and CAPS total; the proportion of treatment "responders" (CGIC rating of "moderately" or "markedly" improved in ability to function at home and work) was also significantly greater with prazosin than placebo, at $64 \%$ versus $27 \%$ respectively. Prazosin was well tolerated in these active-duty soldiers, consistent with the findings of a previous open-label study in 13 active duty soldiers during deployment to Iraq (Calohan et al. 2010).

Interestingly, although in this study behavioral phenotype was not found to predict therapeutic response, a further post hoc analysis was carried out to ask whether any incidentally recorded physiologic indicators of peripheral noradrenergic tone predicted therapeutic response and did obtain a positive result (Raskind et al. n.d.). Specifically, it was theorized that if the efficacy of prazosin is related to interruption of high $\alpha_{1}$ AR mediated signaling, that given the substantial co-regulation of CNS and peripheral noradrenergic systems (Samuels and Szabadi 2008), prazosin efficacy for PTSD symptoms 
might be predicted by a peripheral biomarker of $\alpha_{1}$ AR signaling. In particular, NA stimulation of $\alpha_{1}$ ARs on peripheral arterioles increases blood pressure, particularly while standing (Reid 1986). As the possibility that those with elevated blood pressures might be more likely to benefit from prazosin was also felt to be highly consistent with the researchers' clinical observations, a reanalysis of the relationship of various blood pressure parameters and prazosin response was carried out using the data from the original study.

When the effects of standing systolic and other blood pressure parameters on PTSD outcome measures were analyzed using a linear mixed effects model, it was found that in participants randomized to prazosin, each $10 \mathrm{mmHg}$ increase in pre-treatment standing systolic blood pressure resulted in an additional 14 point reduction (improvement) of the CAPS total score at study end point $(p=0.002)$. All other combinations of pre-treatment blood pressure parameters and PTSD outcome measures either demonstrated trends in the predicted direction or were similarly significantly. No effect of pretreatment blood pressure on outcomes in the group assigned to placebo was found.

These results are consistent with $\alpha_{1}$ AR activation contributing to PTSD pathophysiology, at least in a subgroup of patients - a finding potentially consistent with an earlier observation by Southwick et al that a group of 26 patients with PTSD were roughly divisible into a group with indications of sensitization of the noradrenergic system, and a largely separate group with evidence of sensitization of the serotonergic system (Southwick et al. 1997). Furthermore, these results suggest that elevated standing blood pressure may be a biomarker that can help to identify individuals with combat PTSD likely to benefit from prazosin. However, it should be noted that this study consisted of 57 men and 10 women, with a mean age of $30 \pm 6$ years, all with a history of combat trauma during a deployment. Particularly given the evidence that the relationship between sympathetic activation and blood pressure is significantly lower in younger women than in men or older women (Joyner, Wallin, and Charkoudian 2015), these results cannot be assumed to generalize to women or across the lifespan.

The final RCT of prazosin for PTSD symptoms is actually one of two studies to compare prazosin to an alternative pharmacotherapy for sleep in PTSD. In this RCT, carried out by an independent research group based in Tehran, 102 subjects between 18 and 45 years of age meeting criteria for PTSD (72 male and 30 female) were randomized to prazosin, hydroxyzine (a sedating first-generation antihistamine sometimes used as an anti-anxiety medication, particularly at bedtime), or placebo (Ahmadpanah et al. 2014). A slight majority of subjects' trauma was related to events from the Persian gulf war, with most of the remaining cases resulting from motor vehicle accidents. Self-reported total sleep duration at baseline was approximately 265 minutes, a number more similar to with the population treated by Taylor et al than Germain et al; consistent with this, the baseline PSQI scores were approximately 50\% higher than those in the Germain et al study, as well. Of note, the rate of dose escalation in the prazosin group was more rapid than previous studies, titrating up to $15 \mathrm{mg}$ nightly over 10 days before maintaining at this dose for 6.5 weeks, while hydroxyzine was titrated to $100 \mathrm{mg}$ nightly over the same time period. The authors reported that two individuals were withdrawn from the study because of symptomatic hypotension related to prazosin, but that blood pressures were otherwise not an issue. Improvement in total sleep duration, nightmares and PTSD symptoms were all greater in both active 
treatment groups as compared to the placebo, but with greater improvement in the prazosin group than in the hydroxyzine group; sleep latency, quality and PSQI total were also greater in the two active treatment groups than in placebo, but with no statistically significant differences between the prazosin and hydroxyzine groups. The degree of sleep improvement as measured by the total PSQI score was noted to be significantly correlated with the reduction in PTSD symptom scores $(r=-0.42, p<0.001)$.

These results can be compared to the other publication seeking to compare prazosin to alternative pharmacotherapies for sleep in PTSD, which was a retrospective chart review effectiveness study of prazosin versus quetiapine for nighttime PTSD Symptoms in Veterans carried out by another independent research group (Byers et al. 2010). Quetiapine is a sedating second generation antipsychotic agent that has been widely used for several decades to treat nighttime symptoms in military Veterans. Of the antipsychotics currently available, it has the highest affinity for the $\alpha_{1} A R$, suggesting that it may have some prazosin-like efficacy, as well. In this study, Byers et al reviewed the records of 237 Veterans treated at the Phoenix VA between 2002 and 2006. They found that the medications had equal rates of short term improvement, while prazosin significantly higher rates of long term effectiveness: patients in the prazosin group were significantly more likely to continue therapy to the study end date, significantly less likely to discontinue because of ineffectiveness, and significantly more likely to discontinue because of symptom resolution. Prazosin was also better tolerated, with significantly fewer patients discontinuing therapy because of adverse effects. Finally, substitution of one drug for the other also favored prazosin, with $25 \%$ of the 175 subjects initially treated with quetiapine switching to prazosin during the study period, while only $8 \%$ of the 44 patients initially treated with prazosin were switched to quetiapine. In addition to the differential rates of efficacy versus adverse events, this observation is also consistent with the generally increasing utilization of prazosin for PTSD in the US Veterans Health System every year from 2001 to 2012, in a pattern that was initially related to facility geographic proximity to Seattle, Washington, but has since become more homogeneously prescribed across the United States Veterans Affairs Medical Centers (Friedman 2015; Lund et al. 2012) (R.Rosenheck, personal communication).

Clinical and pre-clinical evidence for the efficacy of prazosin in disorders commonly comorbid with PTSD

There are also multiple clinical and pre-clinical indications that prazosin may be useful for treating several conditions that have been noted to be highly comorbid with PTSD, including postconcussive headaches and alcohol addiction. The use of prazosin for persistent postconcussive symptoms following mild traumatic brain injury (mTBI) was first explored by Dr. Robert Ruff, who carried out a large open label observational study of 74 Veterans who had served in Iraq and Afghanistan, who met criteria for $\mathrm{mTBI}$, and had both persistent post-concussive headaches and some form of residual neurocognitive deficits at a point at least 8 months out from their exposure (Ruff et al. 2012; Ruff, Ruff, and Wang 2009). Headaches are a highly prevalent symptom in this population, and usually resemble migraines phenomenologically (Theeler and Erickson 2012) but are often unresponsive to standard migraine prophylactic treatment (Erickson 2011). They are highly comorbid with PTSD (Ruff et al. 2009), and, in fact, it has been suggested that a common mechanism of autonomic dysregulation and in particular increased sympathetic activation may underlie some of the frequent comorbidity (Takahashi, Hinson, 
and Baguley 2015; Toklu and Tümer 2015; Williamson et al. 2013). Consistent with this, 71 of the 74 subjects in the study by Ruff et al also met criteria for a diagnosis of PTSD, and only two reported having restful sleep without nightmares.

The Veterans were provided a multimodal treatment that included counselling on sleep hygiene that was tailored for a population with military PTSD, along with a titration of prazosin up to $7 \mathrm{mg}$ nightly over four weeks. At nine weeks, substantial improvement was apparent in multiple domains. The percentage of subjects endorsing restorative sleep increased from $7 \%$ to $88 \%$, average headache pain and frequency were reduced by $44 \%$ and $61 \%$, respectively, performance on Montreal Cognitive Assessment (MoCA) (Nasreddine and Phillips 2005) improved from 24, representing mild cognitive impairment, to 28 , which is in the normal range, and subject's subjective reporting of daytime sleepiness on the Epworth sleepiness scale (Johns 2000) decreased from 15 to 7; all of these changes were highly statistically significant and maintained at 6 months. A randomized, controlled trial is necessary, however, in order to confirm these encouraging open-label results.

There have also been both preclinical and clinical studies exploring the role of prazosin in treating alcohol addiction. These studies were motivated in part by clinical experience with Veterans like the two whose stories were presented above whose alcohol addiction remitted following treatment with prazosin, as well as by epidemiologic findings documenting the shared vulnerability for anxiety disorders and alcohol use disorders (AUDs) (Merikangas et al. 1998), in support of the idea that AUDs may arise in part by interaction of alcohol with the stress response system, and by earlier preclinical results which found that not only is acute withdrawal from alcohol associated with increase sympathetic nervous system activity, but that even after several months of abstinence there are persistent alterations in the corticotropin-releasing factor (CRF) / noradrenaline / adrenaline signaling and response pathways (Ehrenreich et al. 1997; Patkar 2003).

The possibility of a role for prazosin in treating AUDs was first tested in animal models by Dennis Rasmussen in our research group at the VA Puget Sound, in collaboration with the Koob laboratory at Scripps Institute and the Froehlich laboratory at the University of Indiana. In rats made alcohol dependent, antagonism of the $\alpha_{1}$ AR by prazosin blocked increases in operant self-administration of ethanol following a period of abstinence (Walker et al. 2008). In genetically alcohol preferring rats, prazosin substantially reduced voluntary alcohol consumption (Rasmussen et al. 2009). Doxazosin, an $\alpha_{1}$ AR antagonist with a longer duration of action than prazosin, also reduced drinking in these genetically alcohol preferring rats (O'Neil et al. 2012). Finally, given the clinical experience with Veterans such as those described above who had achieved sustained abstinence on a combination of prazosin and propranolol, the effects on alcohol consumption in genetically alcohol preferring rats of the $\beta$ AR antagonist propranolol alone was compared to that of prazosin alone and the combination propranolol and prazosin (Rasmussen et al. 2014). While propranolol alone had no consistent effects on alcohol ingestion, adding propranolol to prazosin decreased alcohol ingestion significantly more than prazosin alone, consistent with the possibility that combined $\alpha_{1} A R$ and $\beta$ AR blockade may prove to be a particularly effective regimen for the treatment of AUD. 
There have been two pilot clinical studies assessing the efficacy of prazosin for the treatment of AUD in humans, both carried out by our research group in collaboration with the research teams of Tracy Simpson and Andy Saxon, also at the Puget Sound VA. In the first, 17 men who met criteria for alcohol dependence and who were actively drinking but seeking to stop were randomized to prazosin or placebo and titrated over two weeks to a maximum dose of $4 \mathrm{mg}$ twice per day and $8 \mathrm{mg}$ at bedtime, which was maintained for four weeks (Simpson et al. 2009). Although one third of the participants were Veterans, none met criteria for PTSD. The results were striking: the mean drinking days per week was less than 1 for the prazosin group versus nearly 5.9 for the placebo group, and mean drinks per week was 2.6 in the prazosin group versus 20.9 in the placebo group, with both differences statistically significant.

The second pilot study randomized 30 individuals (19 men and 11 women) with comorbid PTSD and alcohol dependence to the same titration of prazosin versus placebo (Simpson et al. 2015). Again prazosin resulted in significantly fewer drinking days per week and significantly fewer total drinks per week compared with placebo. Surprisingly, however, in this context prazosin did not result in a decrease in subjective ratings of PTSD symptoms. Interestingly, this pattern is consistent with several previous pharmacotherapy interventions for comorbid alcohol dependence and PTSD (Simpson et al. 2015). One possible interpretation of this finding may be that participants were in effect titrating their alcohol use to maintain a relatively steady level of PTSD symptoms. Alternatively, the lack of efficacy for PTSD symptoms may also be related to the lower maximum nighttime prazosin dose or differences in the study population.

This work has also been expanded by an independent research team, which found that prazosin significantly reduced alcohol craving in alcohol dependent persons when they were studied in a laboratory environment (Fox et al. 2012). Currently, a larger RCT of prazosin for alcohol use disorders both with and without comorbid PTSD in active duty military service members is underway.

\section{Integrative view of basic science and clinical results in understanding the role of NA in the CNS and the pathophysiology of PTSD}

The clinical impact of $\alpha_{1}$ noradrenergic receptor blockade in PTSD and commonly comorbid disorders suggests that increased noradrenergic tone plays an important role in their pathophysiology. These findings can inform us as we integrate earlier and more recent basic science results regarding the role of noradrenaline in CNS function, and how alterations in these systems contribute to clinical symptoms. For the sake of brevity, we focus here on the role of NA in the activation and intensity of hyperarousal and threat response systems, although the role of the noradrenergic system in memory consolidation, particularly as modulated by sleep, is also likely important in this context (Deliens, Gilson, and Peigneux 2014; Genzel et al. 2015; Goldstein and Walker 2014; Pace-Schott, Germain, and Milad 2015a, 2015b; Vanderheyden et al. 2014).

The amygdala and locus ceruleus as major stress-response systems in the brain 
The CNS contains several 'stress response systems', with the amygdala generally considered the primary hub of valence and affect generation (Janak and Tye 2015; Keifer et al. 2015). The basolateral amygdala (BLA) receives significant multimodal sensory input in addition to strong reciprocal connectivity with the orbital and medial prefrontal cortical (MPFC) areas and the hippocampus; this is expected to facilitate both recognition of sensory and cognitive cues suggesting the appropriate affective response to a given situation, and modulation via the mPFC and contextual cues from the hippocampus (Milad, Rosenbaum, and Simon 2014). The BLA also has primarily unidirectional outputs to structures associated with coordinating the response to stimuli, such as the central nucleus of the amygdala (CeA). The $\mathrm{CeA}$ coordinates many of the more stereotyped responses to fear or other emotional stimuli, often via modulation of brainstem regions that regulate the peripheral autonomic nervous system. It is also a major site of both acute and persistent modulation by higher-order brain regions and generalized neuromodulatory systems (Keifer et al. 2015).

One particularly important neuromodulatory pathway for the $\mathrm{CeA}$ is via corticotropin-releasing factor (CRF (Kovács 2013)). CRF was initially discovered as the factor released by the parvocellular cells of the periventricular hypopthalamus ( $\mathrm{PVH}$ ) onto the median eminence, promoting the release of adrenocorticotropic hormone ( $\mathrm{ACTH}$ ) from the pituitary and thus stimulating the hypothalamic-pituitary axis (HPA) to prompt peripheral physiologic responses to a systemic stress. It was later found to have a more general neuromodulatory role in the CNS, with its dominant mechanism of action being the activation of the adenylyl cyclase-protein kinase A pathway via G-protein coupled receptors (Hauger et al. 2006). Increased CSF concentrations of CRF have been linked to increased fear and startle responses both in animal models (Coplan et al. 1996; Kalin, Shelton, and Davidson 2000) and in clinical populations with PTSD (Baker et al. 1999; D. J. Bremner et al. 1997). CRF signaling is closely integrated with amygdalar functioning, as is underscored by the amygdala and functionally integrated bed nucleus of the stria terminalis (BNST)'s prominence as the primary sources of CRF outside of the PVH, the amydala's role in stimulating $\mathrm{CRH}$ release from the $\mathrm{PVH}$, and the importance of CRF in circuitry within the amygdala (Davis et al. 2010). The amygdala is not, however, the only stress response system in the CNS (Feinstein et al. 2013), and as we will see in more detail later, CRF also has a major role in coordinating the activity of the amygdala and another major stress-response system, the noradrenergic system (Kovács 2013).

The locus ceruleus (LC) and other central noradrenergic nuclei are also well connected to turn on and modulate the intensity of fear responses both in the CNS and the PNS (Samuels and Szabadi 2008). To explore their role further, particularly given the clinical evidence of prazosin's efficacy in treating even the daytime hyperarousal symptoms of PTSD, researchers in our group started with a previously used mouse model of PTSD that involves exposure to a single 10 second footshock, followed by weekly reminders of the shock (Pynoos et al. 1996). To maximize its relevance to human populations, where significant variation in susceptibility to PTSD is observed, this protocol was modified to include a test before and after the protocol of each mouse's acoustic startle reflex (ASR), so that the mice could be segregated into three groups: those that showed a strong increase in ASR relative to baseline, which were considered "susceptible" mice, those that showed a minimal increase in ASR relative to baseline, 
which were considered "resilient" mice, and those that demonstrated an intermediate phenotype, which were excluded from further analysis (Olson et al. 2011).

Susceptible, resilient, and control (no footshock) mice were then compared both in terms of their neuroanatomic response to stress and their behavioral phenotype. In the first analysis, activation of stress-response related areas of the brain was assessed by c-fos one hour after a 15 minute forced swim test. Compared with both resilient and control mice, susceptible mice showed significantly increased stress-induced activation in the LC, the CeA, and the ventral tegmental area (VTA). In contrast, resilient mice showed significantly increased stress-induced activation in the basal amygdala (a division of the BLA) and significantly decreased stress-induced activation in the ventral BNST relative to both control and susceptible mice. These findings reinforce the evidence that multiple stress-related neural systems, including the LC, demonstrate altered functioning following exposure to stress - particularly in those who demonstrate persistent sequelae. When they characterized the behavioral phenotype, Olson and colleagues found that susceptible mice were significantly more aggressive than either control or resilient mice, but demonstrated significantly less time spent in other types of social interaction, as compared to either control or resilient mice. Both of these effects, however, were normalized by either prazosin or the $\alpha_{2}$ AR agonist clonidine, adding basic science support to the pre-existing clinical indications of the relevance of noradrenergic signaling to the behavioral characteristics of PTSD (see also results of (McCall et al. 2015) and (Rajbhandari, Baldo, and Bakshi 2015), below).

The possibility that a lasting change in LC function following severely stressful experiences could be related to PTSD pathophysiology was also explored in a rat model using electrophysiological techniques by George and colleagues (George et al. 2013). Using a previously developed animal model designed to replicate features of human PTSD known as single prolonged stress (SPS) (Isreal Liberzon et al. 1999), rats were exposed to a three significant stressors (restraint, forced swim, and ether exposure) followed by a quiescent period of, in this paper, between 3 and 9 days; during this time control rats were left in their home cages. Single unit recordings were then made from the LC in anesthetized mice, recording either baseline firing or firing rates following a stereotyped pinching of the animal's paw. Mice with a history of SPS exposure were actually found to have a slightly lower baseline firing rate $(p<.05)$, but a significantly higher evoked firing rate $(p<.01)$. The characteristics of the evoked response were also different, with the higher initial firing rate followed by a longer period of decreased firing rate compared to neurons from control mice.

Although it can be hard to interpret changes in activity in the anesthetized state to expected behavioral outcomes, similarly to Olson et al, George and also assessed overall noradrenergic LC neuronal activity via in situ hybridization quantification of tyrosine hydroxylase (TH) mRNA. In animals examined directly following a quiescent period, TH mRNA expression was showed a borderline statistically-significant $\sim 50 \%$ decrease in the animals with a history of SPS as compared to control animals. In animals examined following a forced swim test, however, the TH mRNA expression showed a trend towards being increased in SPS animals as compared to control animals. Thus, although direct paired-comparisons are not possible within single animals in this experimental design, these results are suggestive that the overall noradrenergic activity in the LC may parallel that seen electrophysiologically in anesthetized animals, with lower baseline activity but increased responsivity to stress. Together, these results both 
complement the behavioral and c-fos based results of Olson et al, while highlighting the likelihood that LC activity is not simply up or down regulated in PTSD or by prior severe stress exposure, but rather the patterns of release are altered, as well.

\section{Reciprocal connectivity between the amygdala and the locus ceruleus}

This emerging view of multiple interacting stress-response systems raises for translational researchers the questions of how these systems interact, and which system(s) most directly, selectively, and effectively controls the behavioral outputs that lead to distress and impaired functioning in clinical populations. The relative roles of amydalar and LC activation in prompting behaviors seen in animal models of PTSD were recently explored in some detail in a mouse model of stress-induced anxiety-like behavior using a combination of chemogenetics and optogenetics (McCall et al. 2015). McCall and colleagues first determined that wild-type mice responded to a 30 minute period of restraint stress by decreasing the percent of time the spent in the center of an enclosed field (the open field test, or OFT), a commonly used measure of anxiety-like behavior in rodents, and was accompanied by an acute increase in activity in LC-NA neurons via c-fos. Next, they documented that both the increased LC neuronal activation and behavioral anxiety-like response on the OFT were fully blocked by chemogenetic inactivation of the noradrenergic LC neurons immediately prior to the administration of the restraint stress, demonstrating that LC activity was necessary to the stress-induced expression of this behavioral output. Following this, they used optogenetic stimulation to artificially drive noradrenergic LC neurons at a rate similar to that seen in a high-tonic state, and demonstrated that this was able to replicate the subsequent decrease in time-in-center on the OFT seen in the prior experiments, even in the absence of the actual restraint-stress. Furthermore, they found that this behavioral effect was blocked by systemic administration of the $\beta$-AR antagonist propranolol, while systemically-administered prazosin not only did not block the effect, but actually appeared to intensify it.

McCall and colleagues also found that tonic optogenetic stimulation of the noradrenergic LC neurons produced both acute and learned place aversion. Specifically, they determined that high-tonic optogenetic stimulation of noradrenergic LC neurons whenever the mice entered one side of a symmetric, two-sided chamber resulted, in a dose-dependent manner, in decreased time spent in the side on which LC stimulation was occurring during the conditioning experiments, as well as on a day following several days of such conditioning but when the stimulation was no longer being performed. This behavioral effect, however, was not blocked by systemically-administered propranolol, but was completely prevented by systemically-administered prazosin. The authors note that this separability in the anxiety-like versus aversion-based behaviors may indicate that anxiety and aversion are distinct in their neurobiologic implementation. Another possible interpretation of this difference, however, may lie in the more highly hippocampal-dependent nature of the place aversion task as compared to the OFT, as the hippocampus is notable for its moderate- to high-density of $\alpha_{1}$ ARs (Zilles et al. 1991, 1993), which serve a highly divergent role in electrophysiologic exploration than hippocampal $\beta$ ARs (Curet and de Montigny 1988).

In addition to demonstrating that noradrenergic LC activity was both sufficient to drive these behavioral effects but that the downstream circuitry appeared to depend on different subtypes of ARs, McCall and 
colleagues also explored the upstream regulation of the LC in the context of initial restraint stress. Based on significant previous pharmacologic and anatomic evidence suggesting that CRF release from the amygdala stimulates LC neurons (Kovács 2013; Valentino and Van Bockstaele 2008), they postulated that amygdalar release of CRF, activating postsynaptic type 1 CRF receptors (CRF-1R) on noradrenergic LC neurons, might be the proximal link between restraint stress and the LC-mediated behavioral outputs observed. They found that the ability of restraint stress to produce decreased time-in-center on the OFT was at least partially blocked by systemic administration of the CRF-1R antagonist, Antalarmin. They then demonstrated that optogenetic stimulation of CRF+ terminals locally within the LC caused increased tonic firing of the LC neurons similar to that documented previously in response to stressful experiences, and that this stimulation of CRF+ terminals was able to itself drive both the anxiety-like and place aversion behaviors previously shown to result from increased tonic LC activity, in the absence but not in the presence of either intra-LC or systemically delivered CRF-1R antagonists.

This work makes a strong case that two different types of stress-induced anxiety-like behaviors, separable by the type of noradrenergic blockade that interrupts their expression, are both mediated by LC activation, which is in turn induced by the activation of CRF-1R on noradrenergic LC neurons by amygdalar CRF release within the LC. This model is highly consistent with previous work documenting the broader regulatory and stimulatory role CRF plays in the stress-response system (Kovács 2013; Valentino and Van Bockstaele 2008). The relationship between amygdalar activation and LC activation is, however, reciprocal. The LC sends a dense projection to the central and basal nuclei of the amygdala (Jones and Moore 1977; Szabadi 2013), with $\alpha_{1}$ ARs appearing to be the most common receptor type, but $\alpha_{2}$ and $\beta$ ARs - including, at least in some places, heterotopic $\alpha_{2}$ ARs - present in each major amygdalar region, as well (Buffalari and Grace 2007; Szabadi 2013).

The coexistence of these different, intermingled receptor types increases the complexity of potential responses that can be seen in response to different concentrations of NA. In particular, $\alpha_{2}$ ARs, which are higher-affinity for NA than $\alpha_{1}$ or $\beta$ ARs (Arnsten 2000), are more active even at lower NA concentrations, while higher concentrations of NA activate $\alpha_{1}$ and $\beta$ ARs more strongly. In the BLA, presynpatic heterotopic $\alpha_{2}$ ARs act primarily to dampen BLA neuronal activation (DeBock et al. 2003), inhibiting both spontaneous and evoked firing (Buffalari and Grace 2007), and suppressing LTP and LTD (DeBock et al. 2003). Thus, low levels of NA release - such as would be expected to result from low-tonic activation of the $\mathrm{LC}$ - act to inhibit both reactivity and memory formation in response to incidental stimuli (Arnsten et al. 2015). As NA levels in the amygdala increase, however, $\alpha_{1}$ ARs and $\beta$ ARs are increasingly activated, and appear to act synergistically to increase amygdalar reactivity and memory formation in response to stimuli (Arnsten et al. 2015; Ferry, Roozendaal, and McGaugh 1999).

Finally, increased noradrenergic signaling also acts at multiple points to facilitate amygdalar output and downstream effects, particularly CRF-mediated signaling (Koob 1999). Within the central nucleus of the amygdala, a large population of CRF-releasing neurons - including many that project to the LC - have been found to receive direct noradrenergic input (Kravets et al. 2015). In this same location, increasing $\beta$ $A R$ activation has been found to upregulate gene expression of CRF as well as $\beta$ ARs themselves during a stress - in this case, early cocaine withdrawal - a process blocked by the application of a specific $\beta 1 \mathrm{AR}$ antagonist (Rudoy, Reyes, and Van Bockstaele 2009). In contrast to this $\beta$ AR mediated pathway, 
stimulation of the $\alpha_{1}$ AR has been found to promote release of CRF from the PVN (Arnsten et al. 1999; Feldman and Weidenfeld 1996; Kiss and Aguilera 1992), an effect that can be blocked by prazosin (Kiss and Aguilera 1992).

\section{Second order modulation of amygdala activity and output by noradrenaline}

In addition to these relatively direct reciprocal effects of CRF on LC activity and NA on amygdalar function, there are a number of second-order regulatory effects likely to have functional significance. Electrophysiological results in anesthetized rats have demonstrated that in the context of repeated stress exposure, the effects of moderate NA on the BLA appeared to switch from predominantly $\alpha_{2}$ ARmediated inhibitory effects to predominantly $\alpha_{1}$ AR-mediated excitatory effects (Buffalari and Grace 2009). Recently, Rajbhandari and colleagues further explored the mechanism behind this effect, in the context of a behavioral output measure - prepulse inhibition - chosen to be a likely analogue of a component of the hyperarousal and, in particular, hyperstartle responses seen in PTSD (Rajbhandari et al. 2015). They found that the effect was mediated by the activation of CRF1Rs on BLA projection neurons during the time of the stress exposure, which resulted in a long-lasting sensitization of $\alpha_{1}$ ARs co-localized on the same projection neurons. In this way, acute stress, acting via a CRF-1R dependent mechanism, appears capable of setting a gain control on the future activity of $\alpha_{1}$ AR activation of the BLA. This result is consistent with the much earlier findings by Southwick and colleagues that PTSD-like responses to yohimbine-triggered increases in NA signaling were greater than expected based on the estimated increase in NA release (Southwick et al. 1993), thereby implicating increased postsynaptic responsivity as part of the pathophysiology of PTSD, and forming part of the theoretical basis for the initial clinical use of prazosin in Veterans with PTSD.

NA signaling can also indirectly modulate amygdalar function, via its influences on the medial prefrontal cortex (mPFC), one of the primary modulators of amydala activity (Dunsmoor and Paz 2015). In the mPFC, decades of work by Arnsten and colleagues have teased apart a situation that is nearly the inverse of that seen in the amygdala (Arnsten et al. 2015). Here, noradrenergic signaling strong enough to activate the lower-affinity $\alpha_{1}$ ARs appears to activate a CAMP and PKC mediated signaling cascade that opens a potassium channel positioned between the synapse, located on a dendritic spine, and the neuronal cell body. This results in the shunting of much of the depolarization caused by NMDA-R mediated synaptic signaling, and thus decreases the responsivity of the PFC neuron to its synaptic inputs. In contrast, lower levels of noradrenaline will preferentially activate the higher-affinity $\alpha_{2}$ ARs, which act via a post-synaptic mechanism on this same pathway in order to strengthen the responsiveness of the neuron to its synaptic inputs.

In this way, a synergistic effect is expected: when low levels of noradrenaline are being released, the predominantly $\alpha_{2}$ AR mediated signaling strengthens prefrontal activity, both facilitating focused cognitive activity and enhancing the ability of the MPFC to inhibit the responses of the amygdala, just as the predominantly $\alpha_{2}$ AR mediated signaling in the amygdala is also causing net inhibition of amydalar responses. In contrast, in the presence of either high levels of noradrenergic signaling or following sensitization or upregulation of $\alpha_{1}$ ARs, the opposite effect would be expected to occur, with net inhibition of PFC functioning combined with higher levels of activity and reactivity in the amgydala. This 
pattern of signaling would be expected to result in decreased focused attention and high levels of affective arousal and reactivity, consistent with the clinical picture of PTSD (Arnsten et al. 2015). This model also illustrates a mechanism by which at least some aspects of PTSD clinical symptoms might be observed to respond to both $\alpha_{1} A R$ antagonism and $\alpha_{2}$ AR agonism, although the relative efficacy of these two intervention strategies may well be expected to vary depending on the relative upregulation of NA release versus $\alpha_{1}$ AR sensitization or upregulation.

\section{Conclusions}

Together, clinical and basic research results both point to dysregulation in an interacting web of brain stress-response systems as fundamental to the pathophysiology of PTSD, and potentially to several of its highly comorbid conditions. They suggest that noradrenaline plays some essential role in the perpetuation and/or expression of clinical symptoms, and that blocking in particular the $\alpha_{1}$ AR can prevent or significantly decrease the expression of many - but not all - of the symptoms of PTSD. Finally, they highlight the importance going forwards of looking at these systems as dysregulated rather than simply up- or down-regulated; of looking at what may sometimes be related but separable pathways by which different symptoms are generated; and of keeping in mind the evidence for heterogeneity in the mechanisms by which symptoms are generated and expressed in different individuals. Looking forwards, the further development and validation of noninvasive measures for quantifying noradrenergic system functioning in humans is likely to be important in advancing our understanding of the relevance of many of these basic science results to clinical populations, and in guiding the development of novel and even more effective clinical interventions. 


\section{Acknowledgements and Disclosures:}

The writing of this manuscript was supported by the Department of Veterans Affairs Office of Academic Affiliations Advanced Fellowship Program in Mental Illness Research and Treatment, the Medical Research Service of the Puget Sound Veterans Affairs Health Care System, and the Puget Sound Veterans Affairs Health Care System Mental Illness Research, Education, and Clinical Center (MIRECC).

Dr. Raskind is a paid advisory board member for Pfizer Laboratories, Merck, and Takeda Pharmaceuticals. Dr. Hendrickson reports no financial relationships with commercial interests.

The views expressed are those of the authors and do not reflect the official policy of the Department of the Army, the Department of Defense or the U.S. Government. 


\section{References:}

Agorastos, Agorastos and Astrid C. E. Linthorst. 2016. "Potential Pleiotropic Beneficial Effects of Adjuvant Melatonergic Treatment in Posttraumatic Stress Disorder." Journal of Pineal Research 124. Retrieved (http://doi.wiley.com/10.1111/jpi.12330).

Ahmadpanah, Mohammad et al. 2014. "Comparing the Effect of Prazosin and Hydroxyzine on Sleep Quality in Patients Suffering from Posttraumatic Stress Disorder." Neuropsychobiology 69(4):23542. Retrieved (http://www.karger.com?doi=10.1159/000362243).

Ajilore, O., R. Stickgold, C. D. Rittenhouse, and J. A. Hobson. 1995. "Nightcap: Laboratory and HomeBased Evaluation of a Portable Sleep Monitor." Psychophysiology 32(1):92-98. Retrieved January 12, 2016 (http://www.ncbi.nlm.nih.gov/pubmed/7878174).

Anderson, E. A., C. A. Sinkey, and A. L. Mark. 1991. "Mental Stress Increases Sympathetic Nerve Activity during Sustained Baroreceptor Stimulation in Humans." Hypertension 17(4 Suppl):II143-49. Retrieved September 9, 2015 (http://www.ncbi.nlm.nih.gov/pubmed/2013492).

Arnsten, Amy F. T. 2000. "Through the Looking Glass: Differential Noradrenergic Modulation of Prefrontal Cortical Function." Neural Plasticity 7(1-2):133-46.

Arnsten, Amy F. T., Rex Mathew, Ravi Ubriani, Jane R. Taylor, and Bao Ming Li. 1999. "Alpha-1 Noradrenergic Receptor Stimulation Impairs Prefrontal Cortical Cognitive Function." Biological Psychiatry 45(1):26-31.

Arnsten, Amy F. T., Murray a. Raskind, Fletcher B. Taylor, and Daniel F. Connor. 2015. "The Effects of Stress Exposure on Prefrontal Cortex: Translating Basic Research into Successful Treatments for Post-Traumatic Stress Disorder." Neurobiology of Stress 1:89-99. Retrieved (http://linkinghub.elsevier.com/retrieve/pii/S2352289514000101).

Baker, D. G. et al. 1999. "Serial CSF Corticotropin-Releasing Hormone Levels and Adrenocortical Activity in Combat Veterans with Posttraumatic Stress Disorder." The American journal of psychiatry 156(4):585-88.

Basile, A. S. and T. V Dunwiddie. 1984. "Norepinephrine Elicits Both Excitatory and Inhibitory Responses from Purkinje Cells in the in Vitro Rat Cerebellar Slice." Brain research 296(1):15-25. Retrieved (http://www.ncbi.nlm.nih.gov/pubmed/6713205).

Beissner, Florian, Karin Meissner, Karl-Jürgen Bär, and Vitaly Napadow. 2013. "The Autonomic Brain: An Activation Likelihood Estimation Meta-Analysis for Central Processing of Autonomic Function." The Journal of neuroscience : the official journal of the Society for Neuroscience 33(25):10503-11.

Retrieved September 10, 2015

(http://www.pubmedcentral.nih.gov/articlerender.fcgi?artid=3685840\&tool=pmcentrez\&renderty pe=abstract).

Belkin, Molly and Thomas Schwartz. 2015. "Alpha-2 Receptor Agonists for the Treatment of Posttraumatic Stress Disorder." Drugs in Context 4:1-5. Retrieved (http://www.drugsincontext.com/alpha-2-receptor-agonists-for-the-treatment-of-posttraumaticstress-disorder/).

Bernardy, Nancy C. and Matthew J. Friedman. 2015. "Psychopharmacological Strategies in the Management of Posttraumatic Stress Disorder (PTSD): What Have We Learned?" Current psychiatry reports 17(4):564. Retrieved May 2, 2016 
(http://www.ncbi.nlm.nih.gov/pubmed/25749751).

Bertram, Franziska et al. 2014. "Autonomic Arousal during Actigraphically Estimated Waking and Sleep in Male Veterans with PTSD." Journal of traumatic stress 27:610-17.

Blake, D. D. et al. 1995. "The Development of a Clinician-Administered PTSD Scale." Journal of traumatic stress 8(1):75-90. Retrieved April 30, 2015 (http://www.ncbi.nlm.nih.gov/pubmed/7712061).

Blanchard, E. B., L. C. Kolb, T. P. Pallmeyer, and R. J. Gerardi. 1982. "A Psychophysiological Study of Post Traumatic Stress Disorder in Vietnam Veterans." The Psychiatric quarterly 54(4):220-29. Retrieved September 15, 2015 (http://www.ncbi.nlm.nih.gov/pubmed/7187510).

Blanchard, Edward B., Lawrence C. Kolb, Annabel Prins, Sherman Gates, and Guy C. McCoy. 1991. "Changes in Plasma Norepinephrine to Combat-Related Stimuli among Vietnam Veterans with Posttraumatic Stress Disorder." The Journal of ... 179(6):371-73. Retrieved September 15, 2015 (http://journals.Iww.com/jonmd/Abstract/1991/06000/Changes_in_Plasma_Norepinephrine_to_C ombat_Related.12.aspx).

Bogerts, Bernhard. 1981. "A Brainstem Atlas of Catecholaminergic Neurons in Man, Using Melanin as a Natural Marker." Journal of Comparative Neurology 197(1):63-80.

Bosch, Jos A., Enno C. I. Veerman, Eco J. de Geus, and Gordon B. Proctor. 2011. "A-Amylase As A Reliable And Convenient Measure Of Sympathetic Activity: Don't Start Salivating Just Yet!"

Psychoneuroendocrinology 36(4):449-53. Retrieved

(http://dx.doi.org/10.1016/j.psyneuen.2010.12.019).

Bremner, Douglas J. et al. 1997. "Elevated CSF Corticotropin-Releasing Factor Concentrations in Posttraumatic Stress Disorder." American Journal of Psychiatry 154(May):624-29.

Bremner, J. D. et al. 1997. "Positron Emission Tomography Measurement of Cerebral Metabolic Correlates of Yohimbine Administration in Combat-Related Posttraumatic Stress Disorder." Archives of General Psychiatry 54(3):246-54. Retrieved December 29, 2015 (http://www.ncbi.nlm.nih.gov/pubmed/9075465).

Brown, R. E., R. Basheer, J. T. McKenna, R. E. Strecker, and R. W. McCarley. 2012. "Control of Sleep and Wakefulness." Physiological Reviews 92(3):1087-1187.

Buckley, T. C. and D. G. Kaloupek. 2001. "A Meta-Analytic Examination of Basal Cardiovascular Activity in Posttraumatic Stress Disorder." Psychosomatic medicine 63(4):585-94.

Buffalari, Deanne M. and Anthony a Grace. 2009. "Chronic Cold Stress Increases Excitatory Effects of Norepinephrine on Spontaneous and Evoked Activity of Basolateral Amygdala Neurons." The international journal of neuropsychopharmacology / official scientific journal of the Collegium Internationale Neuropsychopharmacologicum (CINP) 12(1):95-107. Retrieved (http://www.ncbi.nlm.nih.gov/pubmed/18647435).

Buffalari, Deanne M. and Anthony A. Grace. 2007. "Noradrenergic Modulation of Basolateral Amygdala Neuronal Activity: Opposing Influences of Alpha-2 and Beta Receptor Activation." The Journal of neuroscience : the official journal of the Society for Neuroscience 27(45):12358-66. Retrieved September 17, 2015 (http://www.ncbi.nlm.nih.gov/pubmed/17989300).

Buysse, D. J., C. F. Reynolds, T. H. Monk, S. R. Berman, and D. J. Kupfer. 1989. "The Pittsburgh Sleep Quality Index: A New Instrument for Psychiatric Practice and Research." Psychiatry research 28(2):193-213. Retrieved November 17, 2014 (http://www.ncbi.nlm.nih.gov/pubmed/2748771).

Byers, Melanie G., Kristen M. Allison, Christopher S. Wendel, and Jeannie K. Lee. 2010. "Prazosin Versus Quetiapine for Nighttime Posttraumatic Stress Disorder Symptoms in Veterans." Journal of Clinical 
Psychopharmacology 30(3):225-29. Retrieved

(http://content.wkhealth.com/linkback/openurl?sid=WKPTLP:landingpage\&an=00004714201006000-00002).

Calohan, Jess, Kris Peterson, Elaine R. Peskind, and Murray A. Raskind. 2010. "Prazosin Treatment of Trauma Nightmares and Sleep Disturbance in Soldiers Deployed in Iraq." Journal of traumatic stress 23(5):645-48. Retrieved February 15, 2011 (http://www.ncbi.nlm.nih.gov/pubmed/20931662).

Cascardi, Michele, Davine Armstrong, Leeyup Chung, and Denis Pare. 2015. "Pupil Response to Threat in Trauma-Exposed Individuals with or without PTSD." Journal of traumatic stress 28(4):370-74.

Chou, Chia-Ying, Roberto La Marca, Andrew Steptoe, and Chris R. Brewin. 2014. "Biological Responses to Trauma and the Development of Intrusive Memories: An Analog Study with the Trauma Film Paradigm." Biological Psychology 103:135-43. Retrieved (http://linkinghub.elsevier.com/retrieve/pii/S030105111400180X).

Connor, Daniel F., Damion J. Grasso, Michelle D. Slivinsky, Geraldine S. Pearson, and Alok Banga. 2013. "An Open-Label Study of Guanfacine Extended Release for Traumatic Stress Related Symptoms in Children and Adolescents." Journal of child and adolescent psychopharmacology 23(4):244-51. Retrieved (http://www.pubmedcentral.nih.gov/articlerender.fcgi?artid=3657282\&tool=pmcentrez\&renderty pe=abstract).

Coplan, J. D. et al. 1996. "Persistent Elevations of Cerebrospinal Fluid Concentrations of CorticotropinReleasing Factor in Adult Nonhuman Primates Exposed to Early-Life Stressors: Implications for the Pathophysiology of Mood and Anxiety Disorders." Proceedings of the National Academy of Sciences of the United States of America 93(4):1619-23.

Curet, O. and C. de Montigny. 1988. "Electrophysiological Characterization of Adrenoceptors in the Rat Dorsal Hippocampus. II. Receptors Mediating the Effect of Synaptically Released Norepinephrine." Brain research 475:47-57.

Dahnlstrom, Annica and Kjell Fuxe. 1964. "Evidence for the Existence of Monoamine-Containing Neurons in the Central Nervous System: I. Demonstration of Monoamines in the Cell Bodies of Brain Stem Neurons." Acta Physiologica Scandinavica 62(Supplementum 232):1-55.

Davidson, LM, R. Fleming, and A. Baum. 1987. "Chronic Stress, Catecholamines, and Sleep Disturbance at Three Mile Island." The Journal of Human Stress 13(2):75-83.

Davis, Lori L. et al. 2008. "A Placebo-Controlled Trial of Guanfacine for the Treatment of Posttraumatic Stress Disorder in Veterans." Psychopharmacology bulletin 41(1):8-18. Retrieved December 30, 2015 (http://www.ncbi.nlm.nih.gov/pubmed/18362867).

Davis, Michael, David L. Walker, Leigh Miles, and Christian Grillon. 2010. "Phasic vs Sustained Fear in Rats and Humans: Role of the Extended Amygdala in Fear vs Anxiety." Neuropsychopharmacology: official publication of the American College of Neuropsychopharmacology 35(1):105-35. Retrieved (http://dx.doi.org/10.1038/npp.2009.109).

Day, T. A., J. C. Randle, and L. P. Renaud. 1985. “Opposing Alpha- and Beta-Adrenergic Mechanisms Mediate Dose- Dependent Actions of Noradrenaline on Supraoptic Vasopressin Neurones in Vivo." Brain Research 358:171-79.

DeBock, F. et al. 2003. " $\alpha 2$-Adrenoreceptor Activation Inhibits LTP and LTD in the Basolateral Amygdala: Involvement of Gi/o-Protein-Mediated Modulation of Ca2+-Channels and Inwardly Rectifying K+Channels in LTD." European Journal of Neuroscience 17(7):1411-24. Retrieved September 17, 2015 
(http://www.ncbi.nIm.nih.gov/pubmed/12713644).

Deliens, Gaétane, Médhi Gilson, and Philippe Peigneux. 2014. "Sleep and the Processing of Emotions." Experimental Brain Research 232(5):1403-14.

Dunsmoor, Joseph E. and Rony Paz. 2015. "Fear Generalization and Anxiety: Behavioral and Neural Mechanisms." Biological Psychiatry 78(5):336-43. Retrieved

(http://linkinghub.elsevier.com/retrieve/pii/S0006322315003182).

Edinger, Jack D., Melanie K. Means, Karen M. Stechuchak, and Maren K. Olsen. 2004. "A Pilot Study of Inexpensive Sleep-Assessment Devices." Behavioral sleep medicine 2(1):41-49. Retrieved January 12, 2016 (http://www.ncbi.nlm.nih.gov/pubmed/15600223).

Ehlert, Ulrike, Katja Erni, Gundula Hebisch, and Urs Nater. 2006. "Salivary Alpha-Amylase Levels after Yohimbine Challenge in Healthy Men." Journal of Clinical Endocrinology and Metabolism 91(12):5130-33.

Ehrenreich, H. et al. 1997. "Endocrine and Hemodynamic Effects of Stress versus Systemic CRF in Alcoholics during Early and Medium Term Abstinence." Alcoholism, clinical and experimental research 21(7):1285-93. Retrieved (http://www.ncbi.nlm.nih.gov/pubmed/9347091).

Erickson, Jay C. 2011. "Treatment Outcomes of Chronic Post-Traumatic Headaches after Mild Head Trauma in US Soldiers: An Observational Study." Headache 51(6):932-44. Retrieved (http://www.ncbi.nlm.nih.gov/pubmed/21592097).

Esposito, K., a Benitez, L. Barza, and T. Mellman. 1999. "Evaluation of Dream Content in Combat-Related PTSD." Journal of traumatic stress 12(4):681-87.

Famularo, Richard, Robert Kinscherff, and Terence Fenton. 1988. "Propranolol Treatment for Childhood Posttraumatic Stress Disorder, Acute Type: A Pilot Study." American journal of diseases of children 142(11):1244-47. Retrieved December 30, 2015 (http://www.ncbi.nlm.nih.gov/pubmed/3177336).

Feinstein, Justin S. et al. 2013. "Fear and Panic in Humans with Bilateral Amygdala Damage." Nature Neuroscience 16(3):270-72. Retrieved (http://www.nature.com/doifinder/10.1038/nn.3323).

Feldman, Ruth, Adva Vengrober, Moranne Eidelman-Rothman, and Orna Zagoory-Sharon. 2013. "Stress Reactivity in War-Exposed Young Children with and without Posttraumatic Stress Disorder: Relations to Maternal Stress Hormones, Parenting, and Child Emotionality and Regulation." Development and psychopathology 25(4 Pt 1):943-55. Retrieved (http://www.ncbi.nlm.nih.gov/pubmed/24229541).

Feldman, S. and J. Weidenfeld. 1996. "Involvement of Amygdalar Alpha Adrenoceptors in HypothalamoPituitary-Adrenocortical Responses." Neuroreport 7(18):3055-57.

Fernandez, Sebastian P. and Patricia Gaspar. 2012. "Investigating Anxiety and Depressive-like Phenotypes in Genetic Mouse Models of Serotonin Depletion." Neuropharmacology 62(1):144-54. Retrieved (http://dx.doi.org/10.1016/j.neuropharm.2011.08.049).

Ferry, B., B. Roozendaal, and J. L. McGaugh. 1999. "Involvement of alpha1-Adrenoceptors in the Basolateral Amygdala in Modulation of Memory Storage." European journal of pharmacology 372(1):9-16. Retrieved September 17, 2015 (http://www.ncbi.nlm.nih.gov/pubmed/10374709).

Forbes, David, Mark Creamer, and Dirk Biddle. 2001. "The Validity of the PTSD Checklist as a Measure of Symptomatic Change in Combat-Related PTSD." Behaviour Research and Therapy 39(8):977-86.

Fox, H. C. et al. 2012. "Prazosin Effects on Stress- and Cue-Induced Craving and Stress Response in Alcohol-Dependent Individuals: Preliminary Findings." Alcoholism: Clinical \& Experimental Research 
36(2):351-60. Retrieved (internal-pdf://0728120804/Fox-2012-Prazosin effects on stress- and cuei.pdf \nhttp://ovidsp.ovid.com/ovidweb.cgi?T=JS\&CSC=Y\&NEWS=N\&PAGE=fulltext\&D=medl\&AN=2 1919922http://onlinelibrary.wiley.com/store/10.1111/j.1530-

0277.2011.01628.x/asset/acer1628.pdf?v=1).

Friedman, Matthew J. 2015. "Geographical Diffusion of Prazosin across Veterans Health Administration: Examination of Regional Variation in Daily Dosing and Quality Indicators among Veterans with Posttraumatic Stress Disorder." Journal of Rehabilitation Research \& Development 52(5):619-28.

Genzel, L., V. Spoormaker, B. N. Konrad, and M. Dresler. 2015. "The Role of Rapid Eye Movement Sleep for Amygdala-Related Memory Processing." Neurobiology of Learning and Memory 122:110-21. Retrieved (http://linkinghub.elsevier.com/retrieve/pii/S1074742715000118).

George, Sophie A. et al. 2013. "Altered Locus Coeruleus-Norepinephrine Function Following Single Prolonged Stress." European Journal of Neuroscience 37(6):901-9.

Geracioti, T. D. et al. 2001. "CSF Norepinephrine Concentrations in Posttraumatic Stress Disorder." American Journal of Psychiatry 158(8):1227-30. Retrieved September 15, 2015 (http://www.ncbi.nlm.nih.gov/pubmed/11481155).

Geracioti, Thomas D. et al. 2008. "Effects of Trauma-Related Audiovisual Stimulation on Cerebrospinal Fluid Norepinephrine and Corticotropin-Releasing Hormone Concentrations in Post-Traumatic Stress Disorder." Psychoneuroendocrinology 33(4):416-24.

Germain, Anne et al. 2012. "Placebo-Controlled Comparison of Prazosin and Cognitive-Behavioral Treatments for Sleep Disturbances in US Military Veterans." Journal of psychosomatic research 72(2):89-96. Retrieved May 26, 2012 (http://www.ncbi.nlm.nih.gov/pubmed/22281448).

Goldstein, Andrea N. and Matthew P. Walker. 2014. "The Role of Sleep in Emotional Brain Function." Annual review of clinical psychology 10:679-708. Retrieved (http://www.ncbi.nlm.nih.gov/pubmed/24499013).

Grahnen, Anders, Peter Seideman, Bjorn Lindstrom, Kjell Haglund, and Christer von Bahr. 1981. "Prazosin Kinetics in Hypertension." Clinical Pharmacology \& Therapeutics 30(4):439-46.

Guy, W. 1976. Assessment Manual for Psychopharmacology.

Hauger, Richard L., Victoria Risbrough, Olaf Brauns, and Frank M. Dautzenberg. 2006. "Corticotropin Releasing Factor (CRF) Receptor Signaling in the Central Nervous System: New Molecular Targets." CNS \& neurological disorders drug targets 5(4):453-79. Retrieved (http://www.pubmedcentral.nih.gov/articlerender.fcgi?artid=1925123\&tool=pmcentrez\&renderty pe=abstract).

Horrigan, J. P. and L. J. Barnhill. 1996. "The Suppression of Nightmares with Guanfacine." JOURNAL OF CLINICAL PSYCHIATRY 57(8):371. Retrieved December 30, 2015 (http://www.ncbi.nlm.nih.gov/pubmed/8752021).

Hoskins, M. et al. 2015. "Pharmacotherapy for Post-Traumatic Stress Disorder: Systematic Review and Meta-Analysis." The British Journal of Psychiatry 206(2):93-100. Retrieved (http://bjp.rcpsych.org/cgi/doi/10.1192/bjp.bp.114.148551).

Hughes, Joel W., Michelle E. Feldman, and Jean C. Beckham. 2006. "Posttraumatic Stress Disorder Is Associated with Attenuated Baroreceptor Sensitivity among Female, but Not Male, Smokers." Biological Psychology 71(3):296-302.

Inman, David J., Steven Michael Silver, and Karl Doghramji. 1990. "Sleep Disturbance in Post-Traumatic Stress Disorder: A Comparison with Non-PTSD Insomnia." Journal of Traumatic Stress 3(3):429-37. 
Retrieved (http://dx.doi.org/10.1007/BF00974782).

Janak, Patricia H. and Kay M. Tye. 2015. "From Circuits to Behaviour in the Amygdala." Nature 517:28492.

Johns, Murray W. 2000. "Sensitivity and Specificity of the Multiple Sleep Latency Test (MSLT), the Maintenance of Wakefulness Test and the Epworth Sleepiness Scale: Failure of the MSLT as a Gold Standard." Journal of Sleep Research 9(1):5-11.

Johnson, E. O., T. C. Kamilaris, G. P. Chrousos, and P. W. Gold. 1992. "Mechanisms of Stress: A Dynamic Overview of Hormonal and Behavioral Homeostasis." Neuroscience and Biobehavioral Reviews 16(2):115-30.

Jones, B. E. and R. Y. Moore. 1977. "Ascending Projections of the Locus Coeruleus in the Rat. II. Autoradiographic Study." Brain Research 127(1):23-53. Retrieved September 16, 2015 (http://www.ncbi.nlm.nih.gov/pubmed/301051).

Jones, Lemanuel, Donna Brazel, Elaine R. Peskind, Thomas Morelli, and Murray A. Raskind. 2000. "Group Therapy Program for African-American Veterans with Posttraumatic Stress Disorder." Psychiatric Services 51(9):1177-79. Retrieved (http://vh5ge7rw9u.search.serialssolutions.com/ ?ctx_ver=Z39.88-2004\&ctx_enc=info:ofi/enc:UTF8\&rfr_id=info:sid/ProQ\%3Apilots\&rft_val_fmt=info:ofi/fmt:kev:mtx:journal\&rft.genre=article\&rft.j title=Psychiatric+Services\&rft.atitle=Group+therapy+program+for).

Joshi, Siddhartha, Yin Li, Rishi M. Kalwani, and Joshua I. Gold. 2016. "Relationships between Pupil Diameter and Neuronal Activity in the Locus Coeruleus, Colliculi , and Cingulate Cortex Article Relationships between Pupil Diameter and Neuronal Activity in the Locus Coeruleus, Colliculi, and Cingulate Cortex." Neuron 89(1):1-14. Retrieved (http://dx.doi.org/10.1016/j.neuron.2015.11.028).

Joyner, Michael J., B. Gunnar Wallin, and Nisha Charkoudian. 2015. "Sex Differences and Blood Pressure Regulation in Humans." Experimental physiology 0:1-7. Retrieved (http://www.ncbi.nlm.nih.gov/pubmed/26152788).

Kalin, N. H., S. E. Shelton, and R. J. Davidson. 2000. “Cerebrospinal Fluid Corticotropin-Releasing Hormone Levels Are Elevated in Monkeys with Patterns of Brain Activity Associated with Fearful Temperament." Biological psychiatry 47(7):579-85.

Keary, Therese a., Joel W. Hughes, and Patrick a. Palmieri. 2009. "Women with Posttraumatic Stress Disorder Have Larger Decreases in Heart Rate Variability during Stress Tasks." International Journal of Psychophysiology 73(3):257-64. Retrieved (http://dx.doi.org/10.1016/j.ijpsycho.2009.04.003).

Keeshin, Brooks R., Jeffrey R. Strawn, Dorothee Out, Douglas A. Granger, and Frank W. Putnam. 2015. "Elevated Salivary Alpha Amylase in Adolescent Sexual Abuse Survivors with Posttraumatic Stress Disorder Symptoms." Journal of child and adolescent psychopharmacology 25(4):344-50. Retrieved September 14, 2015 (http://www.ncbi.nlm.nih.gov/pubmed/25803321).

Keifer, Orion P., Robert C. Hurt, Kerry J. Ressler, and Paul J. Marvar. 2015. "The Physiology of Fear: Reconceptualizing the Role of the Central Amygdala in Fear Learning." Physiology 30(5):389-401. Retrieved (http://physiologyonline.physiology.org/lookup/doi/10.1152/physiol.00058.2014).

Kibler, Jeffrey L., Kavita Joshi, and Mindy Ma. 2009. "Hypertension in Relation to Posttraumatic Stress Disorder and Depression in the US National Comorbidity Survey." Behavioral medicine (Washington, D.C.) 34(4):125-32.

Kimble, Matthew O., Kevin Fleming, Carole Bandy, Julia Kim, and Andrea Zambetti. 2010. “Eye Tracking 
and Visual Attention to Threating Stimuli in Veterans of the Iraq War." Journal of Anxiety Disorders 24(3):293-99. Retrieved (http://dx.doi.org/10.1016/j.janxdis.2009.12.006).

Kinzie, J. D. and Paul Leung. 1989. "Clonidine in Cambodian Patients with Posttraumatic Stress Disorder." Journal of Nervous and Mental Disease 177(9):546-50.

Kinzie, J. D., R. L. Sack, and C. M. Riley. 1994. "The Polysomnographic Effects of Clonidine on Sleep Disorders in Posttraumatic Stress Disorder: A Pilot Study with Cambodian Patients." The Journal of nervous and mental disease 182(10):585-87. Retrieved

(http://ovidsp.ovid.com/ovidweb.cgi?T=JS\&PAGE=reference\&D=med3\&NEWS=N\&AN=7931208).

Kiss, A. and G. Aguilera. 1992. "Participation of Alpha 1-Adrenergic Receptors in the Secretion of Hypothalamic Corticotropin-Releasing Hormone during Stress." Neuroendocrinology 56(2):153-60. Retrieved December 18, 2015 (http://www.ncbi.nlm.nih.gov/entrez/query.fcgi?db=pubmed\&cmd=Retrieve\&dopt=AbstractPlus\& list_uids=1328915).

Kobayashi, Ihori, Joseph Lavela, and Thomas A. Mellman. 2014. "Nocturnal Autonomic Balance and Sleep in PTSD and Resilience." Journal of traumatic stress 27:712-16.

Kolb, LC, BS Burns, and S. Griffiths. 1984. "Propranolol and Clonidine in the Treatment of the Chronic Posttraumatic Stress Disorders of War." Pp. 97-107 in Post Traumatic Stress Disorder: Psychological and Biological Sequelae, edited by B. van der Kolk. Washington D.C.: American Psychiatric Press.

Koob, George F. 1999. "Corticotropin-Releasing Factor, Norepinephrine, and Stress." Biological Psychiatry 46(9):1167-80.

Kosten, T. R., J. W. Mason, E. L. Giller, R. B. Ostroff, and L. Harkness. 1987. "Sustained Urinary Norepinephrine and Epinephrine Elevation in Post-Traumatic Stress Disorder." Psychoneuroendocrinology 12(1):13-20.

Kovács, Krisztina J. 2013. "CRH: The Link between Hormonal-, Metabolic- and Behavioral Responses to Stress." Journal of Chemical Neuroanatomy 54:25-33.

Kramer, M. and Lois Kinney. 1988. "Sleep Patterns in Trauma Victims with Disturbed Dreaming." Psychiatry Journal 13(1):12-16. Retrieved October 8, 2015 (http://psycnet.apa.org/psycinfo/198905114-001).

Kravets, JL, Beverly A. S. Reyes, EM Unterwalkd, and Elisabeth J. Van Bockstaele. 2015. "Direct Targeting of Peptidergic Amygdalar Neurons by Noradrenergic Afferents: Linking Stress-Integrative Circuitry." Brain Structure Function 220(1):541-58.

Krystal, John H. and Alexander Neumeister. 2009. "Noradrenergic and Serotonergic Mechanisms in the Neurobiology of Posttraumatic Stress Disorder and Resilience." Brain Research 1293:13-23. Retrieved (http://dx.doi.org/10.1016/j.brainres.2009.03.044).

Liberzon, Israel, James L. Abelson, Shelly B. Flagel, Jonathan Raz, and Elizabeth a. Young. 1999. "Neuroendocrine and Psychophysiologic Responses in PTSD: A Symptom Provocation Study." Neuropsychopharmacology 21(1):40-50.

Liberzon, Isreal, J. F. López, S. B. Flagel, D. M. Vázquez, and E. a. Young. 1999. “Differential Regulation of Hippocampal Glucocorticoid Receptors mRNA and Fast Feedback: Relevance to Post-Traumatic Stress Disorder." Journal of Neuroendocrinology 11(1):11-17.

van Liempt, Saskia et al. 2013. "Sympathetic Activity and Hypothalamo-Pituitary-adrenal Axis Activity during Sleep in Post-Traumatic Stress Disorder: A Study Assessing Polysomnography with 
Simultaneous Blood Sampling." Psychoneuroendocrinology 38(1):155-65. Retrieved (http://linkinghub.elsevier.com/retrieve/pii/S0306453012001928).

Lund, Brian C., Nancy C. Bernardy, Bruce Alexander, and Matthew J. Friedman. 2012. "Declining Benzodiazepine Use in Veterans With Posttraumatic Stress Disorder." Journal of Clinical Psychiatry 73(3):292-96.

Malloy, P. F., J. A. Fairbank, and T. M. Keane. 1983. "Validation of a Multimethod Assessment of Posttraumatic Stress Disorders in Vietnam Veterans." Journal of consulting and clinical psychology 51(4):488-94. Retrieved September 15, 2015 (http://www.ncbi.nlm.nih.gov/pubmed/6619355).

McAinsh, J. and J. M. Cruickshank. 1990. "Beta-Blockers and Central Nervous System Side Effects." Pharmacology \& therapeutics 46(2):163-97.

McCall, Jordan G. G. et al. 2015. "CRH Engagement of the Locus Coeruleus Noradrenergic System Mediates Stress-Induced Anxiety." Neuron 87(3):605-20. Retrieved (http://linkinghub.elsevier.com/retrieve/pii/S0896627315006066).

McFall, M. E., R. C. Veith, and M. M. Murburg. 1992. "Basal Sympathoadrenal Function in Posttraumatic Distress Disorder." Biological psychiatry 31(10):1050-56. Retrieved September 15, 2015 (http://www.ncbi.nlm.nih.gov/pubmed/1511075).

Mellman, Thomas A., Denver D. Brown, Ericka S. Jenifer, Maria M. S. Hipolito, and Otelio S. Randall. 2009. "Posttraumatic Stress Disorder and Nocturnal Blood Pressure Dipping in Young Adult African Americans." Psychosomatic medicine 71(6):627-30.

Mellman, Thomas A., Bethany R. Knorr, Wilfred R. Pigeon, J. C. Leiter, and Metin Akay. 2004. "Heart Rate Variability during Sleep and the Early Development of Posttraumatic Stress Disorder." Biological Psychiatry 55(9):953-56.

Mellman, Thomas a., Adarsh Kumar, Renee Kulick-Bell, Mahendra Kumar, and Bruce Nolan. 1995. "Nocturnal/daytime Urine Noradrenergic Measures and Sleep in Combat-Related PTSD." Biological Psychiatry 38(3):174-79.

Merikangas, Kathleen R. et al. 1998. "Comorbidity of Substance Use Disorders with Mood and Anxiety Disorders: Results of the International Consortium in Psyhiatric Epidemiology." Addictive Behaviors 23(6):893-907. Retrieved May 8, 2012

(http://www.sciencedirect.com.offcampus.lib.washington.edu/science/article/pii/S030646039800 0768).

Michopoulos, Vasiliki, Seth Davin Norrholm, and Tanja Jovanovic. 2015. "Diagnostic Biomarkers for Posttraumatic Stress Disorder: Promising Horizons from Translational Neuroscience Research." Biological Psychiatry 78(5):344-53. Retrieved September 16, 2015 (http://linkinghub.elsevier.com/retrieve/pii/S0006322315000657).

Milad, Mohammed R., Blake L. Rosenbaum, and Naomi M. Simon. 2014. "Neuroscience of Fear Extinction: Implications for Assessment and Treatment of Fear-Based and Anxiety Related Disorders." Behaviour research and therapy 62:17-23. Retrieved (http://www.sciencedirect.com/science/article/pii/S0005796714001351).

Minassian, Arpi et al. 2014. "Heart Rate Variability Characteristics in a Large Group of Active-Duty Marines and Relationship to Posttraumatic Stress." Psychosomatic medicine 76(4):292-301. Retrieved (http://www.ncbi.nlm.nih.gov/pubmed/24804881).

Morilak, David A. et al. 2005. "Role of Brain Norepinephrine in the Behavioral Response to Stress." Progress in Neuro-Psychopharmacology and Biological Psychiatry 29(8):1214-24. Retrieved 
September 8, 2015 (http://www.ncbi.nlm.nih.gov/pubmed/16226365).

Murburg, M. M., M. E. McFall, N. Lewis, and R. C. Veith. 1995. "Plasma Norepinephrine Kinetics in Patients with Posttraumatic Stress Disorder." Biological psychiatry 38(12):819-25. Retrieved (http://www.ncbi.nlm.nih.gov/pubmed/8750041).

Murphy, Peter R., Redmond G. O'Connell, Michael O'Sullivan, Ian H. Robertson, and Joshua H. Balsters. 2014. "Pupil Diameter Covaries with BOLD Activity in Human Locus Coeruleus." Human Brain Mapping 35(8):4140-54.

Murphy, Peter R., Ian H. Robertson, Joshua H. Balsters, and Redmond G. O'connell. 2011. "Pupillometry and P3 Index the Locus Coeruleus-Noradrenergic Arousal Function in Humans." Psychophysiology 48(11):1532-43.

Napadow, Vitaly et al. 2008. "Brain Correlates of Autonomic Modulation: Combining Heart Rate Variability with fMRI." Neurolmage 42(1):169-77.

Nappi, Carla M., Sean P. a Drummond, and Joshua M. H. Hall. 2012. "Treating Nightmares and Insomnia in Posttraumatic Stress Disorder: A Review of Current Evidence." Neuropharmacology 62(2):57685. Retrieved March 12, 2012 (http://www.ncbi.nlm.nih.gov/pubmed/21396945).

Nasreddine, ZS and NA Phillips. 2005. "The Montreal Cognitive Assessment, MoCA: A Brief Screening Tool for Mild Cognitive Impairment." Journal of the ... 53(4):695-99. Retrieved (http://onlinelibrary.wiley.com/doi/10.1111/j.1532-5415.2005.53221.x/full).

Nater, U. M. and N. Rohleder. 2009. "Salivary Alpha-Amylase as a Non-Invasive Biomarker for the Sympathetic Nervous System: Current State of Research." Psychoneuroendocrinology 34(4):48696.

Neylan, Thomas C. et al. 2006. "No Improvement of Posttraumatic Stress Disorder Symptoms with Guanfacine Treatment." The American journal of psychiatry 163(12):2186-88. Retrieved December 30, 2015 (http://www.ncbi.nlm.nih.gov/pubmed/17151174).

Nicholson, Emma L., Richard a. Bryant, and Kim L. Felmingham. 2014. "Interaction of Noradrenaline and Cortisol Predicts Negative Intrusive Memories in Posttraumatic Stress Disorder." Neurobiology of Learning and Memory 112:204-11. Retrieved (http://dx.doi.org/10.1016/j.nlm.2013.11.018).

O’Neil, Meghan L., Lauren E. Beckwith, Carrie L. Kincaid, and Dennis D. Rasmussen. 2012. "The $\alpha(1)$ Adrenergic Receptor Antagonist, Doxazosin, Reduces Alcohol Drinking in Alcohol-Preferring (P) Rats." Alcoholism: Clinical and Experimental Research 37(2):202-12. Retrieved (http://onlinelibrary.wiley.com/doi/10.1111/j.15300277.2012.01884.x/abstract \njsessionid=BE9B82E3839FA85EF6168A7055DBDE09.d01t04\npapers 2://publication/doi/10.1111/j.1530-0277.2012.01884.x).

Olson, Valerie G. et al. 2011. "The Role of Norepinephrine in Differential Response to Stress in an Animal Model of Posttraumatic Stress Disorder." Biological psychiatry 70(5):441-48. Retrieved January 22, 2011 (http://dx.doi.org/10.1016/j.biopsych.2010.11.029).

Pace-Schott, Edward F., Anne Germain, and Mohammed R. Milad. 2015a. "Effects of Sleep on Memory for Conditioned Fear and Fear Extinction." Psychological Bulletin 141(4):835-57.

Pace-Schott, Edward F., Anne Germain, and Mohammed R. Milad. 2015b. "Sleep and REM Sleep Disturbance in the Pathophysiology of PTSD: The Role of Extinction Memory." Biology of mood \& anxiety disorders 5:3. Retrieved (http://www.pubmedcentral.nih.gov/articlerender.fcgi?artid=4450835\&tool=pmcentrez\&renderty pe=abstract). 
Patkar, A. A. 2003. "Changes in Plasma Noradrenaline and Serotonin Levels and Craving During Alcohol Withdrawal." Alcohol and Alcoholism 38(3):224-31. Retrieved (http://www.alcalc.oupjournals.org/cgi/doi/10.1093/alcalc/agg055).

Peskind, Elaine R., Lauren T. Bonner, David J. Hoff, and Murray A. Raskind. 2003. "Prazosin Reduces Trauma-Related Nightmares in Older Men with Chronic Posttraumatic Stress Disorder." Journal of geriatric psychiatry and neurology 16(3):165-71. Retrieved August 15, 2015 (http://www.ncbi.nlm.nih.gov/pubmed/12967060).

Pietrzak, Robert H. et al. 2013. "Association of Posttraumatic Stress Disorder with Reduced in Vivo Norepinephrine Transporter Availability in the Locus Coeruleus." JAMA psychiatry 70(11):11991205. Retrieved (http://www.pubmedcentral.nih.gov/articlerender.fcgi?artid=4026855\&tool=pmcentrez\&renderty pe=abstract).

Pietrzak, Robert H. et al. 2015. "Association of the rs2242446 Polymorphism in the Norepinephrine Transporter Gene SLC6A2 and Anxious Arousal Symptoms of Posttraumatic Stress Disorder." The Journal of Clinical Psychiatry 76(4):e537-38. Retrieved (http://www.psychiatrist.com/jcp/article/pages/2015/v76n04/v76n0426.aspx).

Pole, Nnamdi. 2007. "The Psychophysiology of Posttraumatic Stress Disorder: A Meta-Analysis." Psychological bulletin 133(5):725-46. Retrieved October 2, 2015 (http://www.ncbi.nlm.nih.gov/pubmed/17723027).

Pynoos, Robert S., Ronald F. Ritzmann, Alan M. Steinberg, Armen Goenjian, and loana Prisecaru. 1996. "A Behavioral Animal Model of Posttraumatic Stress Disorder Featuring Repeated Exposure to Situational Reminders." Biological Psychiatry 39(2):129-34.

Rajbhandari, X. Abha K., Brian a Baldo, and Vaishali P. Bakshi. 2015. "Predator Stress-Induced CRF Release Causes Enduring Sensitization of Basolateral Amygdala Norepinephrine Systems That Promote PTSD-Like Startle Abnormalities." 35(42):14270-85.

Raskind, M. A. et al. 2000. "The alpha1-Adrenergic Antagonist Prazosin Ameliorates Combat Trauma Nightmares in Veterans with Posttraumatic Stress Disorder: A Report of 4 Cases." The Journal of clinical psychiatry 61(2):129-33. Retrieved August 15, 2015 (http://www.ncbi.nlm.nih.gov/pubmed/10732660).

Raskind, Murray A. et al. 2002. "Prazosin Reduces Nightmares in Combat Veterans with Posttraumatic Stress Disorder." The Journal of clinical psychiatry 63(7):565-68. Retrieved August 15, 2015 (http://www.ncbi.nlm.nih.gov/pubmed/12143911).

Raskind, Murray A. et al. 2003. "Reduction of Nightmares and Other PTSD Symptoms in Combat Veterans by Prazosin: A Placebo-Controlled Study." The American journal of psychiatry 160(2):37173. Retrieved (http://www.ncbi.nlm.nih.gov/pubmed/12562588).

Raskind, Murray A. et al. 2007. "A Parallel Group Placebo Controlled Study of Prazosin for Trauma Nightmares and Sleep Disturbance in Combat Veterans with Post-Traumatic Stress Disorder." Biol Psychiatry 61(8):928-34. Retrieved March 13, 2012 (http://dx.doi.org/10.1016/j.biopsych.2006.06.032).

Raskind, Murray A. et al. 2013. "A Trial of Prazosin for Combat Trauma PTSD with Nightmares in ActiveDuty Soldiers Returned from Iraq and Afghanistan." American Journal of Psychiatry 170(9):100310. Retrieved July 6, 2015 (http://www.ncbi.nlm.nih.gov/pubmed/23846759).

Raskind, Murray A. et al. n.d. "Higher Pretreatment Blood Pressure Is Associated with Greater PTSD 
Symptom Reduction in Soldiers Treated with Prazosin." (In preparation).

Rasmussen, Dennis D., Laura L. Alexander, Murray A. Raskind, and Janice C. Froehlich. 2009. "The $\alpha_{1}$ Adrenergic Receptor Antagonist, Prazosin, Reduces Alcohol Drinking in Alcohol-Preferring (P) Rats." Alcoholism: Clinical and Experimental Research 33(2):264-72. Retrieved February 15, 2011 (http://www.pubmedcentral.nih.gov/articlerender.fcgi?artid=2692839\&tool=pmcentrez\&renderty pe=abstract).

Rasmussen, Dennis D., Lauren E. Beckwith, Carrie L. Kincaid, and Janice C. Froehlich. 2014. "Combining the $\alpha_{1}$-Adrenergic Receptor Antagonist, Prazosin, with the $B$-Adrenergic Receptor Antagonist, Propranolol, Reduces Alcohol Drinking More Effectively Than Either Drug Alone." Alcoholism: Clinical and Experimental Research 38(6):1532-39. Retrieved (http://doi.wiley.com/10.1111/acer.12441).

Reid, John L. 1986. "Alpha-Adrenergic Receptors and Blood Pressure Control." The American Journal of Cardiology 57(9):E6-12. Retrieved (http://www.sciencedirect.com/science/article/pii/0002914986907162).

Ross, R. J., W. A. Ball, K. A. Sullivan, and S. N. Caroff. 1989. "Sleep Disturbance as the Hallmark of Posttraumatic Stress Disorder." The American journal of psychiatry 146(6):697-707. Retrieved December 22, 2015 (http://www.ncbi.nlm.nih.gov/pubmed/2658624).

Rudoy, Carla A., Arith-Ruth S. Reyes, and Elisabeth J. Van Bockstaele. 2009. "Evidence for beta1Adrenergic Receptor Involvement in Amygdalar Corticotropin-Releasing Factor Gene Expression: Implications for Cocaine Withdrawal." Neuropsychopharmacology : official publication of the American College of Neuropsychopharmacology 34(5):1135-48. Retrieved (http://www.pubmedcentral.nih.gov/articlerender.fcgi?artid=3660858\&tool=pmcentrez\&renderty pe=abstract).

Ruff, Robert L., Ronald G. Riechers, Xiao-Feng Wang, Traci Piero, and Suzanne S. Ruff. 2012. “For Veterans with Mild Traumatic Brain Injury, Improved Posttraumatic Stress Disorder Severity and Sleep Correlated with Symptomatic Improvement." Journal of rehabilitation research and development 49(9):1305-20. Retrieved July 31, 2015 (http://www.ncbi.nlm.nih.gov/pubmed/23408213).

Ruff, Robert L., Suzanne S. Ruff, and Xiao-Feng Wang. 2009. "Improving Sleep: Initial Headache Treatment in OIF/OEF Veterans with Blast-Induced Mild Traumatic Brain Injury." Journal of rehabilitation research and development 46(9):1071-84. Retrieved May 27, 2013 (http://www.ncbi.nlm.nih.gov/pubmed/20437313).

Samuels, E. R. and E. Szabadi. 2008. "Functional Neuroanatomy of the Noradrenergic Locus Coeruleus: Its Roles in the Regulation of Arousal and Autonomic Function Part II: Physiological and Pharmacological Manipulations and Pathological Alterations of Locus Coeruleus Activity in Humans." Current neuropharmacology 6:254-85.

Sara, Susan J. and Sebastien Bouret. 2012. "Orienting and Reorienting: The Locus Coeruleus Mediates Cognition through Arousal." Neuron 76(1):130-41. Retrieved (http://dx.doi.org/10.1016/j.neuron.2012.09.011).

Selye, Hans. 1973. "The Evolution of the Stress Concept." American scientist 61(6):692-99. Retrieved September 10, 2015 (http://www.ncbi.nlm.nih.gov/pubmed/4746051).

Simpson, Tracy L. et al. 2009. "A Pilot Trial of the Alpha-1 Adrenergic Antagonist, Prazosin, for Alcohol Dependence." Alcoholism: Clinical and Experimental Research 33(2):255-63. 
Simpson, Tracy L. et al. 2015. "A Pilot Trial of Prazosin, an Alpha-1 Adrenergic Antagonist, for Comorbid Alcohol Dependence and Posttraumatic Stress Disorder." Alcoholism, clinical and experimental research 39(5):808-17. Retrieved August 15, 2015

(http://www.ncbi.nlm.nih.gov/pubmed/25827659).

Southwick, S. M. et al. 1993. "Abnormal Noradrenergic Function in Posttraumatic Stress Disorder." Archives of general psychiatry 50(4):266-74. Retrieved September 12, 2015 (http://www.ncbi.nlm.nih.gov/pubmed/8466387).

Southwick, Steven M. et al. 1997. "Noradrenergic and Serotonergic Function in Posttraumatic Stress Disorder." Archives of General Psychiatry 54(8):749. Retrieved December 29, 2015 (http://www.ncbi.nlm.nih.gov/pubmed/9283511).

Spoormaker, Victor I. and Paul Montgomery. 2008. "Disturbed Sleep in Post-Traumatic Stress Disorder: Secondary Symptom or Core Feature?" Sleep medicine reviews 12(3):169-84. Retrieved April 5, 2012 (http://www.ncbi.nlm.nih.gov/pubmed/18424196).

Strawn, Jeffrey R. and T. D. Geracioti. 2008. "Noradrenergic Dysfunction and the Psychopharmacology of Posttraumatic Stress Disorder." Depression and Anxiety 25(3):260-71. Retrieved October 2, 2015 (http://www.ncbi.nlm.nih.gov/pubmed/17354267).

Szabadi, Elemer. 2013. "Functional Neuroanatomy of the Central Noradrenergic System." Journal of psychopharmacology (Oxford, England) 27(8):659-93. Retrieved (http://www.ncbi.nlm.nih.gov/pubmed/23761387).

Takahashi, Courtney, Holly E. Hinson, and Ian J. Baguley. 2015. “Autonomic Dysfunction Syndromes after Acute Brain Injury." Handbook of clinical neurology 128:539-51. Retrieved January 12, 2016 (http://www.ncbi.nlm.nih.gov/pubmed/25701906).

Taylor, FB Fletcher B. et al. 2008. "Prazosin Effects on Objective Sleep Measures and Clinical Symptoms in Civilian Trauma Posttraumatic Stress Disorder: A Placebo-Controlled Study." Biol Psychiatry 63(6):629-32. Retrieved May 26, 2012

(http://www.pubmedcentral.nih.gov/articlerender.fcgi?artid=2350188\&tool=pmcentrez\&renderty pe=abstract).

Taylor, Fletcher and Murray A. Raskind. 2002. "The alpha1-Adrenergic Antagonist Prazosin Improves Sleep and Nightmares in Civilian Trauma Posttraumatic Stress Disorder." Journal of clinical psychopharmacology 22(1):82-85. Retrieved August 15, 2015 (http://www.ncbi.nlm.nih.gov/pubmed/11799347).

Tejani-Butt, S. M., W. P. Pare, and J. Yang. 1994. "Effect of Repeated Novel Stressors on Depressive Behavior and Brain Norepinephrine Receptor System in Sprague-Dawley and Wistar Kyoto (WKY) Rats." Brain Research 649(1-2):27-35.

Theeler, Brett J. and Jay C. Erickson. 2012. "Posttraumatic Headache in Military Personnel and Veterans of the Iraq and Afghanistan Conflicts." Current treatment options in neurology 14(1):36-49. Retrieved December 2, 2015 (http://www.ncbi.nlm.nih.gov/pubmed/22116663).

Thoma, Myriam V., Clemens Kirschbaum, Jutta M. Wolf, and Nicolas Rohleder. 2012. "Acute Stress Responses in Salivary Alpha-Amylase Predict Increases of Plasma Norepinephrine." Biological Psychology 91(3):342-48. Retrieved (http://dx.doi.org/10.1016/j.biopsycho.2012.07.008).

Thoma, Myriam Verena, Ljiljana Joksimovic, Clemens Kirschbaum, Jutta Manuela Wolf, and Nicolas Rohleder. 2012. "Altered Salivary Alpha-Amylase Awakening Response in Bosnian War Refugees with Posttraumatic Stress Disorder." Psychoneuroendocrinology 37(6):810-17. Retrieved 
(http://dx.doi.org/10.1016/j.psyneuen.2011.09.013).

Toklu, Hale Zerrin and Nihal Tümer. 2015. "Oxidative Stress, Brain Edema, Blood-Brain Barrier Permeability, and Autonomic Dysfunction from Traumatic Brain Injury." Retrieved January 12, 2016 (http://www.ncbi.nlm.nih.gov/books/NBK299195/).

Tsigos, Constantine and George P. Chrousos. 2002. "Hypothalamic - Pituitary - Adrenal Axis , Neuroendocrine Factors and Stress." 53:865-71.

Turner, R. James and Hiroshi Sugiya. 2002. "Understanding Salivary Fluid and Protein Secretion." Oral diseases 8(1):3-11.

Ulmer, C. S., P. S. Calhoun, H. B. Bosworth, M. F. Dennis, and J. C. Beckham. 2013. "Nocturnal Blood Pressure Non-Dipping, Posttraumatic Stress Disorder, and Sleep Quality in Women." Behavioral Medicine 39(4):111-21.

Valentino, Rita J. and Elisabeth Van Bockstaele. 2008. "Convergent Regulation of Locus Coeruleus Activity as an Adaptive Response to Stress." European Journal of Pharmacology 583(2-3):194-203. Retrieved (http://linkinghub.elsevier.com/retrieve/pii/S0014299908000204).

Vanderheyden, William M., Gina R. Poe, and Israel Liberzon. 2014. "Trauma Exposure and Sleep: Using a Rodent Model to Understand Sleep Function in PTSD." Experimental Brain Research 232(5):157584.

Walker, Brendan M., Dennis D. Rasmussen, Murray A. Raskind, and George F. Koob. 2008. "alpha1Noradrenergic Receptor Antagonism Blocks Dependence-Induced Increases in Responding for Ethanol." Alcohol (Fayetteville, N.Y.) 42(2):91-97. Retrieved February 15, 2011 (http://www.pubmedcentral.nih.gov/articlerender.fcgi?artid=2587143\&tool=pmcentrez\&renderty pe=abstract).

Walker, Matthew P. and Els van der Helm. 2009. "Overnight Therapy? The Role of Sleep in Emotional Brain Processing." Psychological bulletin 135(5):731-48. Retrieved March 9, 2012 (http://www.pubmedcentral.nih.gov/articlerender.fcgi?artid=2890316\&tool=pmcentrez\&renderty pe=abstract).

Westerlund, A. 1985. "Central Nervous System Side-Effects with Hydrophilic and Lipophilic BetaBlockers." European journal of clinical pharmacology 28 Suppl:73-76. Retrieved October 12, 2015 (http://www.ncbi.nlm.nih.gov/pubmed/2865153).

Williamson, John B., Kenneth M. Heilman, Eric C. Porges, Damon G. Lamb, and Stephen W. Porges. 2013. "A Possible Mechanism for PTSD Symptoms in Patients with Traumatic Brain Injury: Central Autonomic Network Disruption." Frontiers in neuroengineering 6:13. Retrieved January 12, 2016 (http://www.pubmedcentral.nih.gov/articlerender.fcgi?artid=3867662\&tool=pmcentrez\&renderty pe=abstract).

Wingenfeld, Katja, Mary A. Whooley, Thomas C. Neylan, Christian Otte, and Beth E. Cohen. 2015. "Effect of Current and Lifetime Posttraumatic Stress Disorder on 24-H Urinary Catecholamines and Cortisol: Results from the Mind Your Heart Study." Psychoneuroendocrinology 52:83-91. Retrieved September 4, 2015 (http://www.ncbi.nlm.nih.gov/pubmed/25459895).

Woodward, Steven H. et al. 2009. "Autonomic Activation During Sleep in Posttraumatic Stress Disorder and Panic: A Mattress Actigraphic Study." Biological Psychiatry 66(1):41-46. Retrieved (http://dx.doi.org/10.1016/j.biopsych.2009.01.005).

Xing, Bo, Yan-Chun Li, and Wen-Jun Gao. 2016. "Norepinephrine versus Dopamine and Their Interaction in Modulating Synaptic Function in the Prefrontal Cortex." Brain Research 1-17. Retrieved 
(http://linkinghub.elsevier.com/retrieve/pii/S0006899316000172).

Young, Elizabeth A. and Naomi Breslau. 2004. "Cortisol and Catecholamines in Posttraumatic Stress Disorder: An Epidemiologic Community Study." Archives of general psychiatry 61(4):394-401. Retrieved September 15, 2015 (http://www.ncbi.nlm.nih.gov/pubmed/15066898).

Zafar, Hanna M., William P. Pare, Shanaz M. Tejani-Butt, W. P. Paré, and Shanaz M. Tejani-Butt. 1997. "Effect of Acute or Repeated Stress on Behavior and Brain Norepinephrine System in Wistar-Kyoto (WKY) Rats." Brain Research Bulletin 44(3):289-95. Retrieved September 12, 2015 (http://www.ncbi.nlm.nih.gov/pubmed/9323444).

Zayfert, Claudia and Jason C. DeViva. 2004. "Residual Insomnia Following Cognitive Behavioral Therapy for PTSD." Journal of traumatic stress 17(1):69-73. Retrieved (http://www.ncbi.nlm.nih.gov/pubmed/15027796).

Zilles, K. et al. 1991. "Regional and Laminar Distributions of Alpha 1-Adrenoceptors and Their Subtypes in Human and Rat Hippocampus." Neuroscience 40(2):307-20. Retrieved August 19, 2015 (http://www.ncbi.nlm.nih.gov/pubmed/1674110).

Zilles, Karl, Meishu Qu, Axel Schleicher, M. Qü, and Axel Schleicher. 1993. "Regional Distribution and Heterogeneity of Alpha-Adrenoceptors in the Rat and Human Central Nervous System." Journal für Hirnforschung 34(2):123-32. Retrieved August 19, 2015 (http://www.ncbi.nlm.nih.gov/pubmed/7901270).

Zoladz, Phillip R. and David M. Diamond. 2013. "Current Status on Behavioral and Biological Markers of PTSD: A Search for Clarity in a Conflicting Literature." Neuroscience and Biobehavioral Reviews 37(5):860-95. Retrieved (http://dx.doi.org/10.1016/j.neubiorev.2013.03.024).

van Zwieten, P. A. 1999. "Centrally Acting Antihypertensive Drugs. Present and Future." Clinical and experimental hypertension 21(5-6):859-73. Retrieved December 30, 2015 (http://www.ncbi.nlm.nih.gov/pubmed/10423108). 


\begin{tabular}{|c|c|c|c|c|c|c|c|c|c|}
\hline Citation & $\begin{array}{l}\mathbf{N} \\
(\% \\
\text { male) }\end{array}$ & $\begin{array}{l}\text { Population } \\
\text { (mean age) }\end{array}$ & $\begin{array}{l}\text { Inclusion } \\
\text { criteria: PTSD } \\
\text { (mean at } \\
\text { baseline) }\end{array}$ & $\begin{array}{l}\text { Inclusion } \\
\text { criteria: sleep } \\
\text { (mean at } \\
\text { baseline) } \\
\end{array}$ & $\begin{array}{l}\text { Study duration } \\
\text { and design }\end{array}$ & $\begin{array}{l}\text { Dosing of } \\
\text { prazosin }\end{array}$ & $\begin{array}{l}\text { Major Outcome } \\
\text { Measures }\end{array}$ & $\begin{array}{l}\text { Results (unless } \\
\text { otherwise specified, } \\
\text { all effects listed } \\
\text { favored prazosin) }\end{array}$ & $\begin{array}{l}\text { Other } \\
\text { notes/comments }\end{array}$ \\
\hline \multirow{5}{*}{$\begin{array}{l}\text { Raskind et al, } \\
2003\end{array}$} & \multirow{5}{*}{$\begin{array}{l}10 \\
(100 \% \\
M)\end{array}$} & \multirow{5}{*}{$\begin{array}{l}\text { Vietnam } \\
\text { Combat } \\
\text { Veterans } \\
\text { (mean age } \\
53 \pm 3 \\
\text { years) }\end{array}$} & \multirow{5}{*}{$\begin{array}{l}\text { Meet DSM-IV } \\
\text { criteria for } \\
\text { PTSD (mean } \\
\text { total CAPS at } \\
\text { baseline }>80 \text { ) }\end{array}$} & \multirow{5}{*}{$\begin{array}{l}\text { CAPS nightmare } \\
\text { item }{ }^{*} \geq 6 / 8 \\
\text { (mean on CAPS } \\
\text { nightmare item } \\
\sim 7 \text {, mean on } \\
\text { CAPS insomnia } \\
\text { item mean } \\
>7 / 8 \text { ) }\end{array}$} & \multirow{5}{*}{$\begin{array}{l}\text { Double-blind } \\
\text { crossover study } \\
\text { with } 3 \text { week } \\
\text { titration period } \\
+6 \text { weeks } \\
\text { maintenance } \\
\text { period in each } \\
\text { arm, plus a } 2 \\
\text { week washout }\end{array}$} & \multirow{5}{*}{$\begin{array}{l}\text { Maximum } \\
10 \mathrm{mg} \\
\text { nightly; } \\
\text { mean } \\
\text { achieved } \\
\text { dose } 9.6 \mathrm{mg} \\
\text { nightly }\end{array}$} & CAPS: nightmares* & $E S=1.9, p<.001$ & \multirow{5}{*}{$\begin{array}{l}\text { Crossover design } \\
\text { limited by } 80 \% \text { of } \\
\text { subjects beginning } \\
\text { in prazosin arm } \\
\text { dropped out } \\
\text { during placebo arm } \\
\text { due to symptom } \\
\text { recurrence }\end{array}$} \\
\hline & & & & & & & CAPS: insomnia ${ }^{*}$ & $E S=1.6, p<.01$ & \\
\hline & & & & & & & CGIC & $E S=1.4, p<.01$ & \\
\hline & & & & & & & Total CAPS & $E S=.7, p<.01$ & \\
\hline & & & & & & & $\begin{array}{l}\text { Individual CAPS } \\
\text { symptom clusters }\end{array}$ & All ES=.6-.7, $p<.001$ & \\
\hline \multirow{5}{*}{$\begin{array}{l}\text { Raskind et al, } \\
2007\end{array}$} & \multirow{5}{*}{$\begin{array}{l}40 \\
(95 \% \\
M)\end{array}$} & \multirow{5}{*}{$\begin{array}{l}\text { Combat } \\
\text { Veterans } \\
\text { (mean age } \\
56 \pm 9 \\
\text { years) }\end{array}$} & \multirow{5}{*}{$\begin{array}{l}\text { Meet DSM-IV } \\
\text { criteria for } \\
\text { PTSD (mean } \\
\text { total CAPS at } \\
\text { baseline } 70 \pm \\
\text { 20) }\end{array}$} & \multirow{5}{*}{$\begin{array}{l}\text { CAPS nightmare } \\
\text { item and CAPS } \\
\text { insomnia item } \\
\text { both } \geq 5 / 8 \\
\text { (mean on } \\
\text { nightmare item } \\
6.5 \pm 1 \text { ) }\end{array}$} & \multirow{5}{*}{$\begin{array}{l}\text { Parallel group } \\
\text { placebo } \\
\text { controlled } \\
\text { study with } 4 \\
\text { week titration + } \\
8 \text { weeks } \\
\text { maintenance }\end{array}$} & \multirow{5}{*}{$\begin{array}{l}\text { Maximum } \\
15 \mathrm{mg} \\
\text { nightly; } \\
\text { mean } \\
\text { achieved } \\
\text { dose } \\
13 \pm 3 \mathrm{mg}\end{array}$} & CAPS: nightmare & $E S=.94, p=.02$ & \multirow{5}{*}{$\begin{array}{l}\text { Trend towards } \\
\text { decrease in all } \\
\text { unpleasant } \\
\text { dreams, but only } \\
\text { sig decrease in } \\
\text { trauma-related } \\
\text { nightmares }\end{array}$} \\
\hline & & & & & & & PSQI & $E S=1.0, p=.008$ & \\
\hline & & & & & & & CGIC & $E S=1.08, p=.002$ & \\
\hline & & & & & & & $\begin{array}{l}\text { PTSD dream rating } \\
\text { scale }(n=22)\end{array}$ & $p<.001$ & \\
\hline & & & & & & & Total CAPS & NS trend, $p=.3$ & \\
\hline \multirow{8}{*}{$\begin{array}{l}\text { Taylor et al, } \\
2008\end{array}$} & \multirow{8}{*}{$\begin{array}{l}13 \\
(15 \% \\
M)\end{array}$} & \multirow{8}{*}{$\begin{array}{l}\text { Civilian } \\
\text { trauma (8 } \\
\text { childhood, } \\
5 \text { adult; } \\
\text { mean age } \\
49 \pm 10 \\
\text { years) }\end{array}$} & \multirow{8}{*}{$\begin{array}{l}\text { Meet DSM-IV } \\
\text { criteria for } \\
\text { PTSD with } \\
\text { total PCL-C } \geq \\
40 \text { (mean } \\
\text { baseline PCL-C } \\
59 \pm 13 \text { ) }\end{array}$} & \multirow{8}{*}{$\begin{array}{l}\text { CAPS nightmare } \\
\& \text { insomnia } \\
\text { items both } \geq \\
4 / 8 \text { (means at } \\
\text { baseline } \sim 4 \text { and } \\
\sim 6, \text { resp.; final } \\
\text { mean total } \\
\text { sleep time in } \\
\text { placebo group } 4 \\
\text { h } 40 \text { min) }\end{array}$} & \multirow{8}{*}{$\begin{array}{l}\text { Double-blind } \\
\text { crossover trial } \\
\text { with } 10 \text { days } \\
\text { titration and } 11 \\
\text { days } \\
\text { maintenance }\end{array}$} & \multirow{8}{*}{ 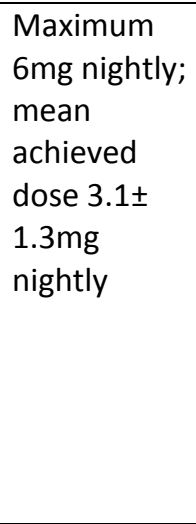 } & Total sleep time & $E S=.98, p<.01$ & \multirow{8}{*}{$\begin{array}{l}2 \text { additional } \\
\text { subjects screened } \\
\text { but excluded after } \\
\text { subjective } \\
\text { dizziness on } 1 \mathrm{mg} \\
\text { test dose given to } \\
\text { all screened } \\
\text { subjects }\end{array}$} \\
\hline & & & & & & & Total REM time & $E S=.62, p<.01$ & \\
\hline & & & & & & & Sleep latency & NS & \\
\hline & & & & & & & CAPS: nightmares & $E S=.96, p=.04$ & \\
\hline & & & & & & & CAPS: insomnia & $\begin{array}{l}\text { NS trend: } \\
E S=.50, p=.35\end{array}$ & \\
\hline & & & & & & & $\begin{array}{l}\text { Distressed } \\
\text { awakenings }\end{array}$ & $E S=.92, p=.05$ & \\
\hline & & & & & & & Total PCL-C & $E S=.79, p=.025$ & \\
\hline & & & & & & & $\begin{array}{l}\text { PTSD dream rating } \\
\text { scale }\end{array}$ & $E S=1.4, p=.006$ & \\
\hline \multirow[t]{5}{*}{$\begin{array}{l}\text { Germain et } \\
a l, 2012\end{array}$} & \multirow{5}{*}{$\begin{array}{l}50 \\
(90 \% \\
M)\end{array}$} & \multirow{5}{*}{$\begin{array}{l}\text { Veterans } \\
\text { (mean age } \\
41 \pm 13 \\
\text { years) }\end{array}$} & \multirow{5}{*}{$\begin{array}{l}\text { Not required } \\
\text { ( } 58 \% \text { of } \\
\text { subjects met } \\
\text { criteria for } \\
\text { PTSD at entry; } \\
\text { mean total } \\
\text { CAPS scores at } \\
\text { baseline were } \\
35,44 \text {, and } 40\end{array}$} & \multirow{5}{*}{$\begin{array}{l}\text { CAPS nightmare } \\
\text { item } \geq 3 \text { and } \\
\text { PSQI } \geq 5 \text { (mean } \\
\text { PSQI } 10.3-11.6 \\
\text { across groups; } \\
\text { mean total } \\
\text { sleep time } 6 \mathrm{~h} \\
15 \text { min across all } \\
3 \text { groups' }\end{array}$} & \multirow{5}{*}{$\begin{array}{l}\text { Double-blind } \\
\text { parallel group } \\
\text { trial with } \\
\text { randomization } \\
\text { to } 3 \text { groups: } \\
\text { prazosin (6 } \\
\text { weeks titration } \\
+2 \text { weeks } \\
\text { maintenance), }\end{array}$} & \multirow{5}{*}{$\begin{array}{l}\text { Maximum } \\
15 \mathrm{mg} \\
\text { nightly; } \\
\text { mean } \\
\text { achieved } \\
\text { dose } 8.9 \pm \\
5.7 \mathrm{mg} \\
\text { nightly }\end{array}$} & $\begin{array}{l}\text { Insomnia severity } \\
\text { index }\end{array}$ & $\begin{array}{l}\text { BSI, prazosin sig } \\
\text { better than placebo }\end{array}$ & \multirow{5}{*}{$\begin{array}{l}\text { Many variables \& } \\
\text { low baseline } \\
\text { symptoms meant } \\
\text { statistical power } \\
\text { limited. Eg, } \\
\text { nightmare freq } \\
\text { decreased by } 70 \% \\
\text { in the prazosin } \\
\text { group while }\end{array}$} \\
\hline & & & & & & & PSQI & NS & \\
\hline & & & & & & & $\begin{array}{l}\text { PSQI addendum for } \\
\text { PTSD }\end{array}$ & NS & \\
\hline & & & & & & & Sleep diary & NS & \\
\hline & & & & & & & CGIC & $\begin{array}{l}\text { BSI, prazosin both } \\
\text { NS trend > placebo }\end{array}$ & \\
\hline
\end{tabular}




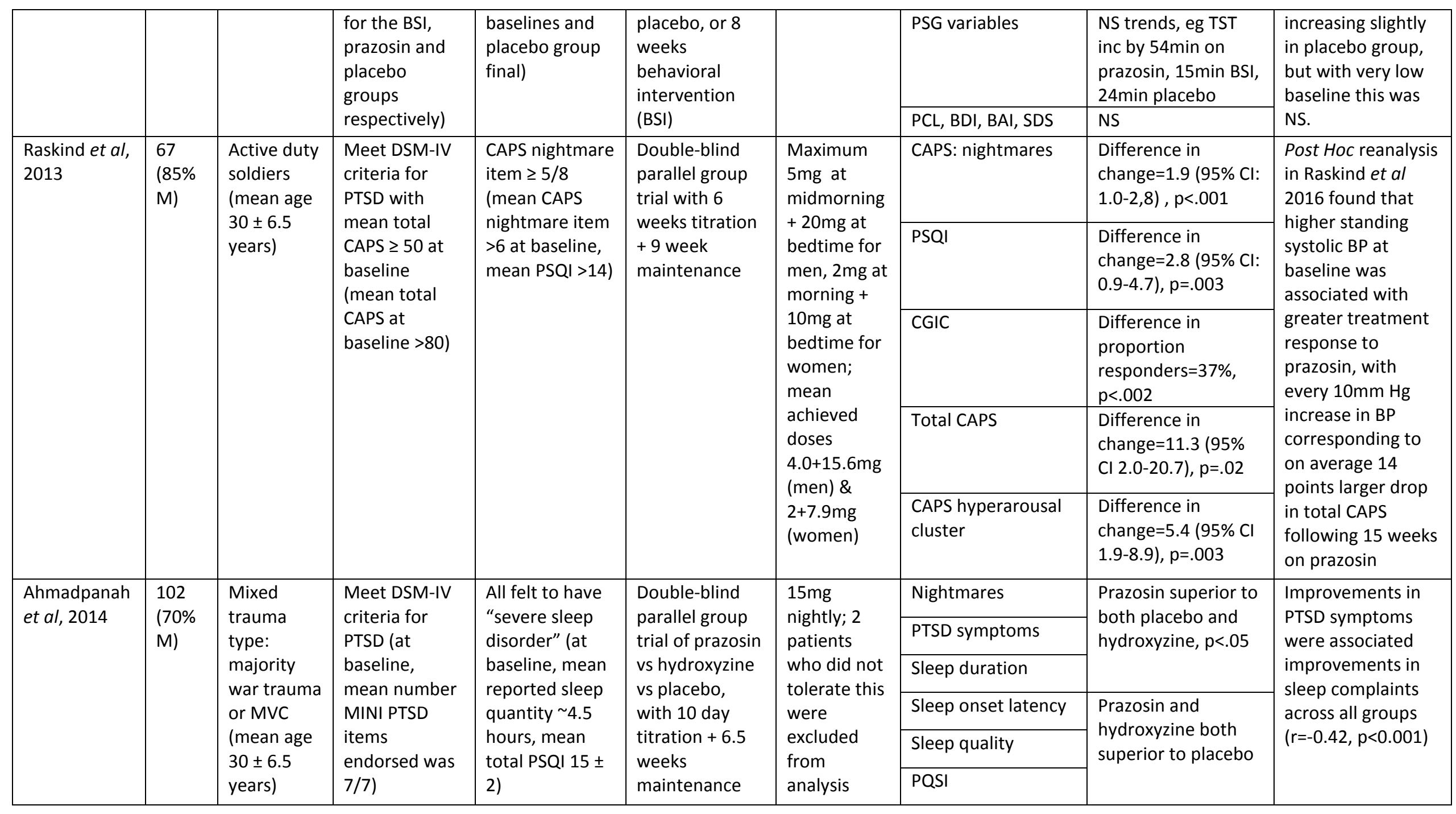

Abbreviations: BSI (Behavioral Sleep Intervention), CAPS (Clinician-Administered PTSD Scale), CGIC (Clinical Global Impressions of Change), ES (Effect Size), MINC (MiniInternational Neuropsychiatric Intake), MVC (Motor Vehicle Collision), PCL-C (PTSD Checklist - Civilian version), PSG (Polysomnography), PSQI (Pittsburgh Sleep Quality Index).

"CAPS nightmare item is item B2, which addresses "recurrent distressing dreams of the event"; CAPS insomnia item is item D1, which addresses "difficulty falling or staying asleep". 